\title{
Optimal ranking regime analysis of TreeFlow dendrohydrological reconstructions
}

\author{
S. A. Mauget \\ USDA-ARS Plant Stress and Water Conservation Laboratory, Lubbock, TX, USA \\ Correspondence to: S. A. Mauget (steven.mauget@.ars.usda.gov)
}

Received: 24 January 2015 - Published in Clim. Past Discuss.: 26 March 2015

Revised: 4 August 2015 - Accepted: 12 August 2015 - Published: 26 August 2015

\begin{abstract}
The optimal ranking regime (ORR) method was used to identify 6-100-year time windows containing significant ranking sequences in 55 western US streamflow reconstructions, and reconstructions of the level of the Great Salt Lake and San Francisco Bay salinity during 1500-2007. The method's ability to identify optimally significant and nonoverlapping runs of low- and high-rankings allows it to reexpress a reconstruction time series as a simplified sequence of regime segments marking intra- to multi-decadal (IMD) periods of low or high streamflow, lake level, and salinity. Those ORR sequences, referred to here as $Z$-lines, can be plotted to identify consistent regime patterns in the analysis of numerous reconstructions. The $Z$-lines for the 57 reconstructions evaluated here show a common pattern of IMD cycles of drought and pluvial periods during the late 16th and 17 th centuries, a relatively dormant period during the 18th century, and the reappearance of alternating dry and wet IMD periods during the 19th and early 20th centuries. Although this pattern suggests the possibility of similarly active and inactive oceanic modes in the North Pacific and North Atlantic, such centennial-scale patterns are not evident in the ORR analyses of reconstructed Pacific Decadal Oscillation (PDO), El Niño-Southern Oscillation, and North Atlantic sea-surface temperature variation. However, given the inconsistency in the analyses of four PDO reconstructions, the possible role of centennial-scale oceanic mechanisms is uncertain. In future research the ORR method might be applied to climate reconstructions around the Pacific Basin to try to resolve this uncertainty. Given its ability to compare regime patterns in climate reconstructions derived using different methods and proxies, the method may also be used in future research to evaluate long-term regional temperature reconstructions.
\end{abstract}

\section{Introduction}

Since the first attempts at tree-ring dating analysis over the western USA, focus has shifted from questions centered on the past to questions related to current and future water management. Whereas the early emphasis was on the dating of prehistoric Native American structures in the US southwest (Nash, 1999; Creasman et al., 2012), subsequent work has tried to better estimate hydrological variability over important watershed areas of the arid American west. Although the first streamflow reconstructions based on tree-ring data were conducted in the 1930s (see Meko and Woodhouse, 2011 for a review), the growth of western population and agricultural production centers in the latter half of the 20th century spurred demand for better estimates of hydrological variability than were available from gauged streamflow data records. A leading example of the re-assessment of a key western US water resource was the Stockton and Jacoby (1976) reconstruction of Colorado River flow at Lees Ferry Arizona. The Colorado River Compact (MacDonnell et al., 1995; Hundley, 2009) was based on a 16.4 million acre-feet (maf) (20.23 billion cubic meters) per year Lees Ferry flow estimate derived from relatively brief gauge records from the period immediately preceding the Compact's 1922 drafting. However, the Stockton and Jacoby (1976) 1512-1961 flow reconstruction varied about an average level of 13.5 maf. As a result, the Compact's equal 7.5 maf division of flow between the upper and lower Colorado basins over-allocated the river's water. Given the experience of more recent western US drought conditions (e.g., Pagano et al., 2004; Woodhouse and Lukas, 2006a; Woodhouse et al., 2006), and doubts that the variability in centennial-scale gauge records reflect what water managers might expect in the near future, the current demand for more representative records of hydro-climate is particu- 
larly clear regarding the intensity, duration, and recurrence of drought (Rice et al., 2009).

In meeting the need for extended proxy records streamflow reconstructions have been conducted over a number of western watershed regions including the upper Snake (Wise, 2010), the upper Colorado (Woodhouse and Lukas, 2006a; Woodhouse et al., 2006; Meko et al., 2007; Gray et al., 2011), the South Platte (Woodhouse and Lukas, 2006a), the Rio Grande (Margolis et al., 2011), the Great Salt Lake (Bekker et al., 2014; DeRose et al., 2014) and California's Central Valley (Meko et al., 2001). The results of many of these reconstructions have been made available via the TreeFlow web data resource (http://treeflow.info). The quantity of data currently available from treeflow.info - 54 TreeFlow reconstructions are evaluated here in addition to flow and lake level reconstructions from other sources - presents both opportunities and challenges. The analysis of multiple reconstructions allows for the possibility of detecting patterns of common pluvial and drought regimes in the pre-instrumental period. However, objectively and consistently identifying these regime periods, and presenting the results in a way that can expose consistent patterns of variation may require new approaches to time series analysis.

One commonly used method to test for regimes in multicentury proxy climate records is runs analysis (Meko et al., 1995, 2007; Biondi et al., 2002, 2005; Gray et al., 2011; Bekker et al., 2014). This approach defines the run duration of extreme flow periods as the number of consecutive highor low-flow years above or below a specified flow threshold. The sum of those flow departures above or below that threshold is referred to as the run magnitude, while the average departure over the run's duration, i.e., the run's magnitude divided by its duration, is the run intensity (Dracup et al., 1980; Biondi et al., 2002). However, as noted by Gray et al. (2011) and Meko and Woodhouse (2011), a basic problem with this method is that single years exceeding the threshold in the midst of otherwise extended runs results in the definition of two individual runs. Also, a drought or pluvial period's magnitude and intensity are dependent on the choice of a subjectively chosen threshold. Thus while runs analysis can provide information about the magnitude and duration of anomalous flow events in a reconstructed streamflow record, its results can be dependent on the choice of threshold and may not provide the most robust estimates of event duration.

A second method that can be used to detect regime periods in climate records is intervention analysis. As described by Box and Tiao (1975) and used by Mantua et al. (1997), intervention analysis involves forming stochastic models that account for the influence of events, or interventions, that lead to abrupt changes in a time series. This iterative process of model identification, fitting, and diagnostic checking assumes prior knowledge of the timing of intervention events. When that timing is not known, candidate regime shifts have been identified via two-sample $t$ tests to detect significant shifts in 15-year sample means before and after each year in a time series (Gedalof and Smith, 2001; D'Arrigo et al., 2005).

In previous work the optimal ranking regime (ORR) method has been used to identify significant intra- to multidecadal (IMD) periods in US temperature, precipitation, and streamflow during the instrumental period (Mauget, 2003a, b, 2004; Cordero et al., 2011; Mauget and Cordero, 2014a, b), and in reconstructed records of South American snowpack based on tree-ring data (Masiokas et al., 2012). This approach ranks a time series' data values, samples those rankings over moving time windows, and then calculates MannWhitney $U$ and $Z$ statistics for each running sample. Conducting this sampling process over running time windows allows for testing every possible ranking sequence occurring over a fixed window duration. By repeating this running sampling using windows of varying widths, the process exhaustively samples the ranking sequences in a time series over a range of timescales. Comparing the magnitudes of the resulting $Z$ statistics for all the ranking samples allows the method to objectively identify a time series' most significant sequences of low or high rankings. The ORR algorithm's simple output - a time series' most significant, nonoverlapping ranking regimes - makes it possible to graphically identify common drought or pluvial regime patterns in the analyses of many hydroclimate reconstructions. Using this graphic approach here may allow for a "big picture" of the reconstructed IMD flow regimes in the current TreeFlow data during 1500-2007. Given that features of climate reconstructions might be sensitive to choices of modeling methodology (Hidalgo et al., 2000; Woodhouse et al., 2006), this may also have a corroborative effect in showing common regime patterns in reconstructions produced by investigators using different methods.

The following section describes the streamflow, lake level, and salinity reconstruction data evaluated here. Section 3 explains the ORR method and demonstrates it on Colorado River at Lees Ferry reconstructed annual flow values during 1500-2005. Section 4 presents the results of the ORR approach on all 57 reconstructed data series during 1500-2010. Section 5 summarizes and discusses Sect. 4 results, outlines the advantages and disadvantages in using the ORR approach in evaluating reconstructed climate series, and proposes possible future research to apply the method to climate reconstructions around the Pacific Basin.

\section{Data}

The dendrohydrological data evaluated here (Table 1) includes 55 streamflow reconstructions, and reconstructions of the level of the Great Salt Lake (DeRose et al., 2014) and San Francisco Bay salinity (Stahle et al., 2001). Figure 1 shows the locations of the USGS gauge stations associated with each flow reconstruction and the general locations of the San Francisco Bay and the Great Salt Lake. 
Although the Sacramento River-Four Rivers reconstruction (Meko et al., 2001) was derived as the sum of four streamflow components in the Sacramento River watershed, its location is marked at the junction of the Sacramento and American rivers. The Stahle et al. (2001) salinity data and all but two of the streamflow records were obtained from treeflow.info. Reconstructed flow values for the Columbia River at The Dalles (Gedalof et al., 2004) was obtained via personal communication with Z'ev Gedalof. Data on the Weber River flow near Oakley, Utah (Bekker et al., 2014), and the level of the Great Salt Lake were obtained from Matthew Bekker and Justin DeRose of the Wasatch Dendroclimatology Research Group. Of Table 1's 57 reconstructions, the shortest is Gedalof et al. (2004) record of annual Columbia River flow (238 years), while the longest is Meko et al. (2007) Colorado River flow at Lees Ferry AZ reconstruction (1241 years). In the following, these stations will be referred to by their Table 1 reconstruction number, i.e., R1, R2,... R57.

Given the goal of detecting patterns of intra-decadal to centennial-scale hydrological regimes over the western USA, a network of streamflow gauge stations with a more uniform geographic distribution than that found in Fig. 1 would be ideal. However, more than one-third of Fig. 1's stations (R19-R36) are concentrated in northern Colorado over the upper watersheds of the Colorado and South Platte rivers. More than three-fourths (R4-R47) are located in three states in the interior western USA - Wyoming, Utah and Colorado (WY-UT-CO). This in part due to the demand of western water managers for better estimates of drought duration and recurrence in key watershed areas of the US central Rockies (e.g., Woodhouse and Lukas 2006a, b, c). Another source of data redundancy is the repetition of reconstructions at gauge stations by different investigators. Flow records for the Green River at Green River, Wyoming (R13, R14), estimated by both Barnett et al. (2010) and Woodhouse et al. (2006) are tested here, as are two records (R52, R53) for the Colorado River at Lees Ferry (Meko et al., 2007; Woodhouse et al., 2006). Finally, some of the Fig. 1 gauge stations measure flow for the same rivers at various points in their watersheds, e.g., the Colorado (R19, R22, R36, R38, R40, R51, R52), the Snake (R2-4) and the Green (R7, R12-14, R17) rivers.

Estimating pre-instrumental annual flow records from tree-ring data takes place in a general framework (Fritts, 1976; Meko et al., 1995; also, see http://treeflow.info/study. html):

- evaluating and conducting quality control of flow data from a gauge location whose flow record is to be extended. If necessary, the data may be adjusted to correct for the effects of diversions or non-climatic trends;

- collecting and evaluating tree-ring data from multiple sites in or near the gauge's watershed region. This includes site selection and tree coring, cross dating the cores from different trees, de-trending of ring width measurements to remove the "age trend" effects of in-

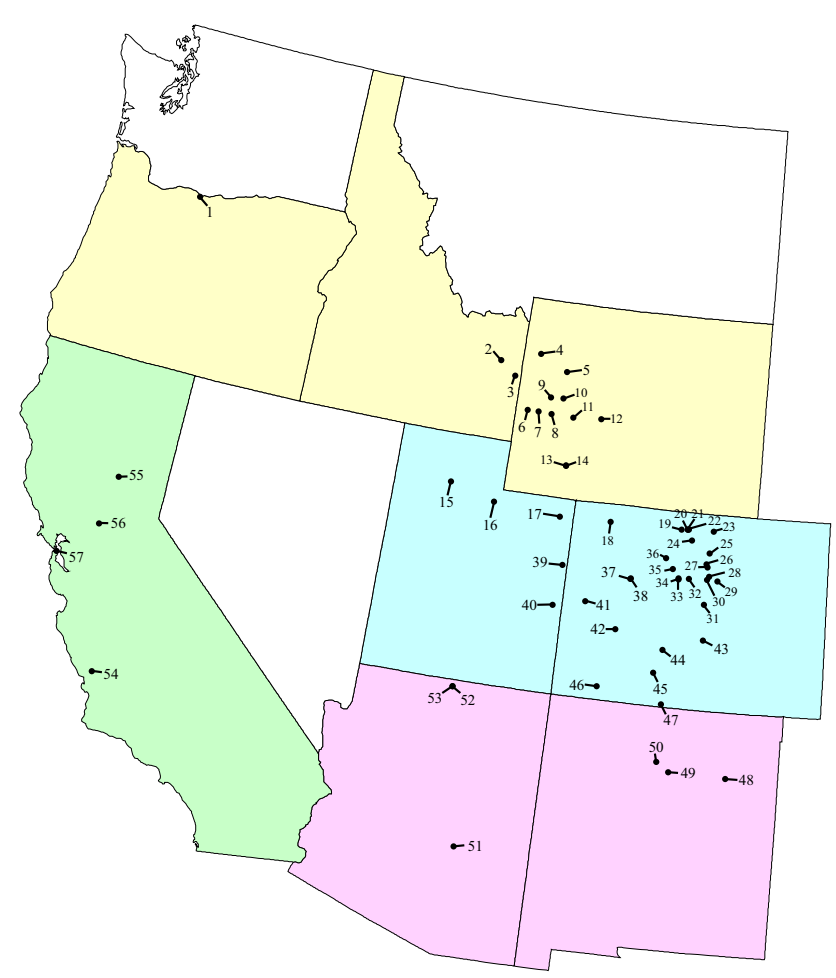

Figure 1. Locations of the USGS gauge stations associated with the Table 1 flow reconstructions and the locations of San Francisco Bay and the Great Salt Lake.

creasing trunk radius, and the removal of biological autocorrelation in ring widths. Finally, the resulting standardized ring width indices for numerous trees at a site are averaged to form a site dendrochronology;

- forming a reconstruction model that estimates annual flow values from a set of predictor site chronologies during a calibration period common to both instrumental flow data and the site chronologies. These models are typically regression models, where the predictor variables can be actual site chronology time series (e.g., Woodhouse and Lukas, 2006a; Watson et al., 2009; Gray et al., 2011), principal component (PC) series derived from the filtered ring width indices of individual trees (Meko, 1997), PC series derived from site chronologies (Woodhouse et al., 2006; Meko et al., 2001; Hidalgo et al., 2000), or PC series derived from flow reconstructions based on individual site chronologies (Meko et al., 2007; Hirschboeck and Meko, 2008);

- validating the reconstruction model using predictor variables and gauge data that were withheld from the regression training process;

- evaluating the calibration and validation statistics. TreeFlow reconstructions report the portion of the annual flow variance explained by the regression model 
Table 1. Reconstruction number, location, beginning year, ending year, calibration period $R^{2}$, validation period reduction of error (RE), and reference or URLs ( ${ }^{* *}=$ http://treeflow.info) for the reconstructions evaluated here. Reconstruction number is abbreviated as "R\#".

\begin{tabular}{|c|c|c|c|c|c|c|}
\hline R\# & Location & $\begin{array}{r}\text { Begin } \\
\text { year }\end{array}$ & $\begin{array}{l}\text { End } \\
\text { year }\end{array}$ & $R^{2}$ & $\mathrm{RE}$ & Reference \\
\hline 1 & Columbia R. at The Dalles, OR & 1750 & 1987 & 0.25 & 0.24 & Gedalof et al. (2004) \\
\hline 2 & Snake R. near Heise, ID & 1591 & 2005 & 0.63 & 0.59 & Wise (2010) \\
\hline 3 & Snake R. near Irwin, ID & 1591 & 2005 & 0.66 & 0.59 & Wise (2010) \\
\hline 4 & Snake R. near Moran, WY & 1591 & 2005 & 0.56 & 0.52 & Wise (2010) \\
\hline 5 & Wind R. near Dubois, WY & 1560 & 1992 & 0.45 & 0.36 & Watson et al. (2009) \\
\hline 6 & Little Popo Agie R. near Lander, WY & 1560 & 1999 & 0.58 & 0.5 & Watson et al. (2009) \\
\hline 7 & Green R. near Daniel, WY & 1615 & 1999 & 0.44 & 0.38 & Barnett et al. (2010) \\
\hline 8 & Pine Creek above Fremont Lake, WY & 1615 & 1999 & 0.53 & 0.48 & Barnett et al. (2010) \\
\hline 9 & East Fork R. near Big Sandy, WY & 1615 & 1999 & 0.58 & 0.51 & Barnett et al. (2010) \\
\hline 10 & Hams Fork near Frontier, WY & 1615 & 1999 & 0.48 & 0.43 & Barnett et al. (2010) \\
\hline 11 & Fontanelle Creek near Fontanelle, WY & 1615 & 1999 & 0.48 & 0.39 & Barnett et al. (2010) \\
\hline 12 & Green R. below Fontanelle Reservoir, WY & 1615 & 1999 & 0.59 & 0.52 & Barnett et al. (2010) \\
\hline 13 & Green R. near Green River, WY & 1525 & 1997 & 0.48 & 0.38 & Woodhouse et al. (2006) \\
\hline 14 & Green R. near Green River, WY & 1615 & 1999 & 0.6 & 0.54 & Barnett et al. (2010) \\
\hline 15 & Great Salt Lake level reconstruction & 1429 & 2005 & 0.5 & 0.2 & DeRose et al. (2014) \\
\hline 16 & Weber R. near Oakley, UT & 1429 & 2004 & 0.49 & 0.29 & Bekker et al. (2014) \\
\hline 17 & Green River near Greendale, UT & 1615 & 1999 & 0.65 & 0.58 & Barnett et al. (2010) \\
\hline 18 & Yampa River near Maybell, CO & 1000 & 2002 & 0.6 & 0.56 & Gray et al. (2011) \\
\hline 19 & Colorado R. at Hot Sulphur Springs, CO & 1566 & 2002 & 0.7 & 0.67 & Woodhouse and Lukas (2006b) \\
\hline 20 & Fraser R. at Granby, CO & 1383 & 1999 & 0.73 & 0.69 & Woodhouse and Lukas (2006a) \\
\hline 21 & Willow Creek Reservoir inflow, $\mathrm{CO}$ & 1383 & 1999 & 0.73 & 0.67 & Woodhouse and Lukas (2006a) \\
\hline 22 & Colorado R. near Granby, CO & 1383 & 1999 & 0.67 & 0.59 & Woodhouse and Lukas (2006a) \\
\hline 23 & Cache la Poudre R. at Canyon Mouth, CO & 1615 & 1999 & 0.64 & 0.56 & Woodhouse and Lukas (2006a) \\
\hline 24 & Big Thompson R. at Mouth of Canyon, CO & 1569 & 1999 & 0.72 & 0.65 & Woodhouse and Lukas (2006a) \\
\hline 25 & St Vrain R. at Lyons, CO & 1571 & 1999 & 0.65 & 0.61 & Woodhouse and Lukas (2006a) \\
\hline 26 & Boulder Creek near Orodell, CO & 1566 & 2002 & 0.64 & 0.6 & Woodhouse and Lukas (2006b) \\
\hline 27 & S. Boulder Creek near Eldorado Springs, CO & 1566 & 2002 & 0.69 & 0.65 & Woodhouse and Lukas (2006b) \\
\hline 28 & Clear Creek near Golden, $\mathrm{CO}$ & 1566 & 2002 & 0.7 & 0.66 & Woodhouse and Lukas (2006c) \\
\hline 29 & N. Fork of South Platte R. at South Platte, CO & 1685 & 1987 & 0.67 & 0.61 & Woodhouse and Lukas (2006a) \\
\hline 30 & South Platte R. at South Platte, CO & 1634 & 2002 & 0.76 & 0.71 & Woodhouse and Lukas (2006a) \\
\hline 31 & South Platte R. below Cheesman Lake, CO & 1685 & 1987 & 0.63 & 0.58 & Woodhouse and Lukas (2006a) \\
\hline 32 & Fraser R. at Winter Park, CO & 1437 & 2002 & 0.67 & 0.62 & Woodhouse and Lukas (2006a) \\
\hline 33 & Williams Fork R. near Leal, CO & 1437 & 2002 & 0.67 & 0.62 & Woodhouse and Lukas (2006a) \\
\hline 34 & Blue R. at Dillon, CO & 1437 & 2002 & 0.63 & 0.59 & Woodhouse and Lukas (2006a) \\
\hline 35 & Blue R. above Green Mountain Reservoir, CO & 1539 & 1999 & 0.76 & 0.7 & Woodhouse and Lukas (2006a) \\
\hline 36 & Colorado River near Kremmling, CO & 1440 & 2002 & 0.7 & 0.64 & **/upco/coloradokremmling.html \\
\hline 37 & Roaring Fork River at Glenwood Springs, CO & 1402 & 1999 & 0.69 & 0.63 & **/upco/roaringfork.html \\
\hline 38 & Colorado River at Glenwood Springs, CO & 1525 & 1997 & 0.72 & 0.65 & Woodhouse et al. (2006) \\
\hline 39 & White River near Watson, UT & 1000 & 2002 & 0.61 & 0.58 & Gray et al. (2011) \\
\hline 40 & Colorado River near Cisco, UT & 1569 & 1997 & 0.77 & 0.73 & Woodhouse et al. (2006) \\
\hline 41 & Gunnison River near Grand Junction, CO & 1569 & 1997 & 0.77 & 0.73 & Woodhouse et al. (2006) \\
\hline 42 & Gunnison River at Crystal Reservoir, CO & 1569 & 1997 & 0.69 & 0.64 & Woodhouse et al. (2006) \\
\hline 43 & Arkansas River at Canon City, CO & 1685 & 1987 & 0.63 & 0.58 & **/ark/arkansascanoncity.html \\
\hline 44 & Saguache Creek near Saguache, CO & 1520 & 2000 & 0.7 & 0.63 & $* * /$ riogr/saguache.html \\
\hline 45 & Rio Grande near Del Norte, CO & 1508 & 2002 & 0.71 & 0.69 & **/riogr/riograndedelnorte.html \\
\hline 46 & Conejos River near Mogote, $\mathrm{CO}$ & 1508 & 2002 & 0.67 & 0.63 & **/riogr/conejos.html \\
\hline 47 & Animas River at Durango, $\mathrm{CO}$ & 1470 & 2002 & 0.82 & 0.8 & **/upco/animas.html \\
\hline 48 & Canadian R. near Sanchez, NM & 1604 & 1997 & 0.61 & 0.51 & $* * /$ ark/canadian.html \\
\hline 49 & Rio Grande at Otowi Bridge, NM & 1450 & 2002 & 0.74 & 0.72 & **/riogr/riograndeotowinrcs.html \\
\hline 50 & Santa Fe River near Santa Fe, NM & 1592 & 2007 & 0.6 & 0.54 & Margolis et al. (2011) \\
\hline 51 & Colorado River at Lees Ferry, AZ & 762 & 2005 & 0.57 & 0.54 & Meko et al. (2007) \\
\hline 52 & Colorado River at Lees Ferry, AZ & 1490 & 1997 & 0.81 & 0.76 & Woodhouse et al. (2006) \\
\hline 53 & Sum of Salt-Verde-Tonto waterways, AZ & 1330 & 2005 & 0.49 & 0.45 & Hirschboeck and Meko (2008) \\
\hline 54 & Salinas R. at Paso Robles, CA & 1409 & 2003 & 0.73 & 0.68 & Griffin (2007) \\
\hline 55 & Sacramento River-Four Rivers index & 901 & 1977 & 0.62 & 0.55 & Meko (2001) \\
\hline 56 & Feather River inflow to Lake Oroville, CA & 901 & 1977 & 0.61 & 0.54 & Meko (2001) \\
\hline 57 & San Francisco Bay salinity & 1604 & 1997 & 0.82 & 0.8 & Stahle et al. (2001) \\
\hline
\end{tabular}


during the calibration period $\left(R^{2}\right)$, the standard error of the estimate during the calibration period, a reduction of error (RE) statistic derived from the validation data, and the root square error of the regression during the validation period;

- applying the model to the full length of the site chronology predictor data to generate reconstructed annual flow values in both the pre-instrumental and instrumental periods.

The $R^{2}$ and RE statistics for each of the reconstructions evaluated here can be found in Table 1. When multiple RE and $R^{2}$ are reported because different validation procedures are used (e.g., Margolis et al., 2011), or when multiple values are reported for different reconstruction periods (e.g., Meko et al., 2007; Hirschboeck and Meko, 2008; Meko et al., 2001), Table 1 shows the lowest RE and $R^{2}$ values. As defined by Cook et al. (1999, Appendix B) RE $>0.0$ indicates predictive skill relative to a regression estimate defined by the calibration period's climatological mean. Table 1's RE scores range between 0.20 (R15) to 0.80 (R57). The median $\mathrm{RE}$ value is 0.59 , and 46 of the RE values are greater than 0.50 .

\section{The optimal ranking regime method}

The ORR method ranks a time series' data values, samples the rankings over running time windows of $n_{\mathrm{I}}$ years' duration, and then converts each sample of rankings into MannWhitney $U$ and $Z$ statistics (Mann and Whitney, 1947). Although the $U$ statistic for rankings within a sample window can be calculated based on the sample size and rank sum (Mendenhall et al., 1990; Wilks, 1995), the statistic is also equal to the total number of data values outside the sampling window that precede each sample value when all data values are arranged by rank (Hollander and Wolfe, 1999). For an $\mathrm{N}$-year reconstructed flow series divided into an $n_{\mathrm{I}}=21$ year sample window and $n_{I I}=\mathrm{N}-21$ years outside the window, the highest possible $U$ statistic occurs when the sample contains the 21 highest ranked years $[U=(\mathrm{N}-21) \times 21]$. A sample containing the 21 lowest ranked years produces the lowest $U$ statistic [ $U=0 \times 21$ ]. Randomly sampled sets of 21 rankings produce $U$ statistics that are normally distributed between those two extreme values, with values in the distribution's lower and upper tails indicating a high incidence of low- and high-ranked values in a sample.
The $U$ distribution's mean is equal to the average of the minimum and maximum $U$ values, e.g.,

$\mu_{0}=0.5[(0 \cdot 21)+(21 \cdot(N-21))]=0.5 \cdot n_{I} \cdot n_{\mathrm{II}}$,

while the standard deviation can be estimated via Eq. (2) (Mendenhall et al., 1990),

$\sigma_{0}=\left(\left(n_{\mathrm{I}} n_{\mathrm{II}} \cdot\left(n_{\mathrm{I}}+n_{\mathrm{II}}+1\right)\right) / 12\right)^{1 / 2}$.

The Gaussian $U$ statistics can be $Z$-normalized using these null parameters, with significantly low (high) $Z$ values indicating a significant incidence of low (high) annual flow rankings relative to a null hypothesis that assumes random sampling $\left(H_{0}\right)$.

$Z_{0}=\frac{U-\mu_{0}}{\sigma_{0}}$

For a specific sample size, the Eq. (1) and (2) solutions for $\mu_{0}$ and $\sigma_{0}$ assume that a sample's rankings are serially independent. However, in a multi-century reconstructed annual flow series, outcomes consistent with persistent "red" variation are more likely in a sampled sequence of rankings. As a result, both null parameters were calculated here via Monte Carlo simulations consistent with a null hypothesis that allows for year-to-year persistence. This hypothesis $\left(H_{1}\right)$ holds that the flow time series represents semi-random climate variation with interannual persistence, but is essentially stationary and trend-less. The parameters of $U$ null distributions consistent with $H_{1}$ were derived here via the following autoregressive (AR) modeling and Monte Carlo procedure:

(i) As $H_{1}$ assumes that the time series is trend-less, AR(1), $\operatorname{AR}(2)$, and $\operatorname{AR}(3)$ regression coefficients were calculated from the autocorrelation values of the detrended reconstruction series. Then, the AR model yielding the minimum Akaike information criteria score was selected (Akaike, 1974).

(ii) The AR model identified in step (i) was used to form AR red noise processes.

(iii) The mean and variance of the red noise process resulting from step (ii) were adjusted to agree with that of the data. Then, red noise series with lengths equal to that of the time series being tested were selected and the values ranked.

(iv) From the ranked noise processes resulting from step (iii), appropriate null statistics were calculated, which in the preceding example would be $U_{\text {I }}$ statistics derived from non-overlapping 21-element segments of each red noise series.

(v) Steps (ii)-(iv) were repeated until 50000 independent null statistics were calculated, and the parameters of the resulting $U_{\mathrm{I}}$ null distribution were determined. 
Given the null distribution parameters derived from these Monte Carlo simulations $\left(\mu_{1}, \sigma_{1}\right)$, the $Z$ statistics of rankings sampled from a reconstruction time series can be used to test $H_{1}$.

$Z_{1}=\frac{U-\mu_{1}}{\sigma_{1}}$

A sample's $Z$ statistic is assigned based on which normalization, $Z_{0}$ or $Z_{1}$, produces the most conservative significance estimate. These assignments are determined mainly by the relative magnitudes of $\sigma_{0}$ and $\sigma_{1}$. Although the Monte Carlogenerated $\mu_{1}$ values agree closely with the corresponding Eq. (1) $\mu_{0}$ values, $\sigma_{1}$ values generated using 6-100-year samples drawn from the rankings of the step (ii) red noise series were usually greater than the corresponding Eq. (2) $\sigma_{0}$ values. In those cases $\left|Z_{1}\right|<\left|Z_{0}\right|$, and $Z$ statistics are calculated via Eq. (4). In instances when the Monte Carlo-generated $\sigma_{1}$ values are less than the $\sigma_{0}$ values, $\left|Z_{1}\right|>\left|Z_{0}\right|$, and significance could be assigned to ranking samples that were consistent with white noise if the Eq. (4) normalization was used. In those cases $U$ statistics are normalized using Eq. (3). As a result, the absolute value of the Eq. (3) $Z_{0}$ statistics serve as a ceiling limiting the magnitudes of $Z$ values, and helps to ensure that significance is not assigned to ranking samples that were consistent with essentially random white noise variation.

Figure 2a-e shows the ORR method applied to the Meko et al. (2007) Colorado River at Lees Ferry (CRLF) flow reconstruction during 1500-2005. Figure 2a shows the annual flow values and their 21-year running mean, while Fig. $2 b$ shows the $Z$ statistics for flow rankings sampled over running 21year windows. The horizontal lines in Fig. $2 b$ mark the $Z$ statistics' negative and positive significance at two-sided 95 and $99 \%$ confidence levels, and a dry and wet shade scheme that marks negative and positive significance at both levels. Figure 2c's dry and wet shade horizontal lines show the 21year ranking regimes indicated as negatively or positively significant at a $95 \%$ or better confidence level in Fig. 2b, superimposed on the CRLF series. The vertical placement of those horizontal regime segments shows the ranking regime's corresponding $Z$ statistic, which is measured on the figure's right axis.

To apply the ORR procedure to an extended range of timescales, $U$ and $Z$ statistics were calculated with moving sampling windows between 6 and 100 years in length. For every sample size, running $Z_{0}$ and $Z_{1}$ statistics were calculated for each time series, and, as described above, $Z$ values were defined by the normalization that produced the smallest $Z$ magnitude. This normalization allows for significance testing of a specific sample size, as in Fig. 2c, but also allows for comparing the significance of $U$ statistics derived using different sample sizes. After normalizing the running $U$ statistics from each analysis, the positive and negative $Z$ statistics from all 95 tests that are significant at a $95 \%$ confidence level are combined as in Fig. 2d. Those pooled
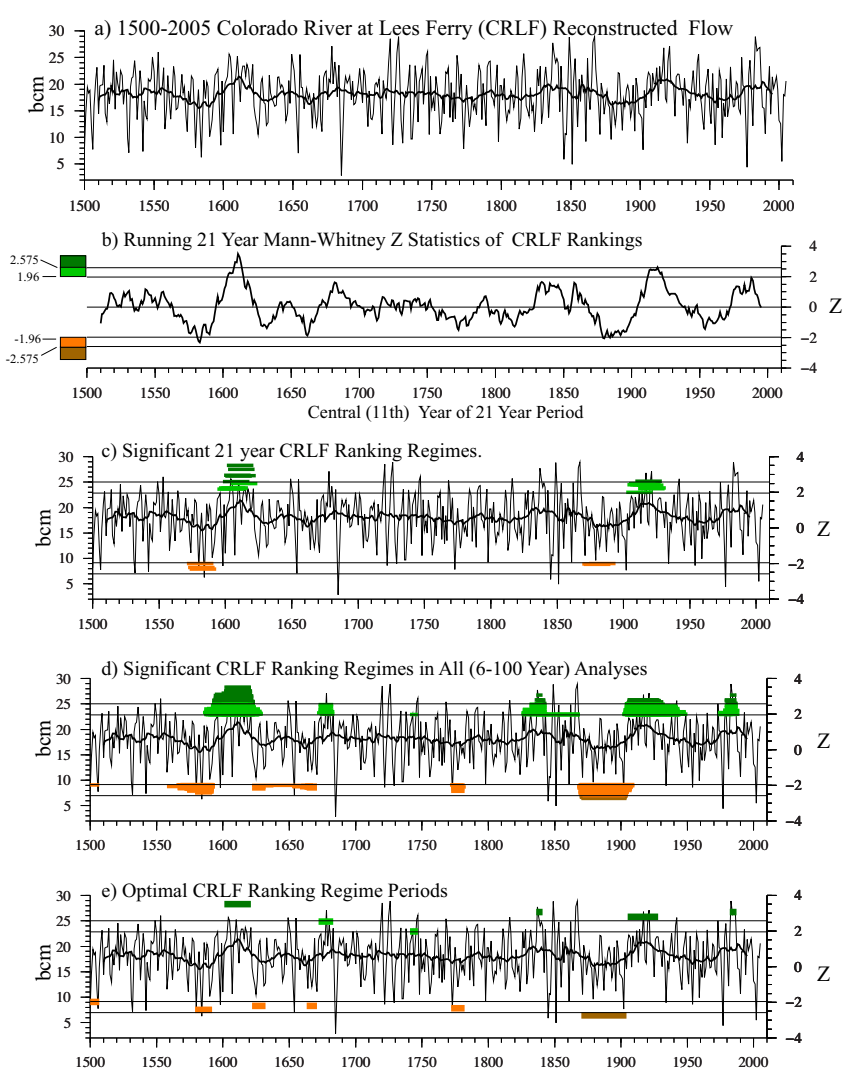

Figure 2. (a) Time series of Colorado River at Lees Ferry reconstructed water year total natural flow (CRLF) during 1500-2005. (b) Mann-Whitney $Z$ statistics of ranked reconstructed flow values sampled over running 21-year time windows. Horizontal lines indicate two-sided $95 \%(Z= \pm 1.96)$ and $99 \%(Z= \pm 2.575)$ confidence intervals. (c) As in (a) with horizontal extent of colored bars showing significant 21-year low- and high-flow ranking regimes as indicated in (b). Vertical placement of bars show corresponding $Z$ values as marked by right axis. Color scheme on left axis shows positive and negative significance at $95 \%$ and $99 \%$ confidence levels. (d) As in (c) with significant low- and high-flow ranking regimes indicated by running Mann-Whitney $Z$ analyses with 6-, 7-,..., 100-year sampling windows. (e) The optimally significant low- and high-flow ranking regimes in (d) occurring over non-overlapping time windows.

statistics are then evaluated to identify ranking sequences that are optimally significant over distinct, non-overlapping time windows (Fig. 2e). This process first sorts all the significant regime periods by the absolute value of the period's $Z$ statistic $(|Z|)$ and then records the most significant statistic and its period. Then, the next most significant $|Z|$ value with a period that does not overlap with the most significant ranking period is recorded. In the Fig. 2e CRLF series, these leading statistics (Table 2) occurred during a 1601-1621 wet regime $(Z=3.498)$ and two 6-year wet regimes with equal rank sums and $Z$ statistics during 1836-1841 and 1982$1987(Z=3.063)$. The ORR algorithm iteratively proceeds by recording the next most significant $|Z|$ statistic with a pe- 

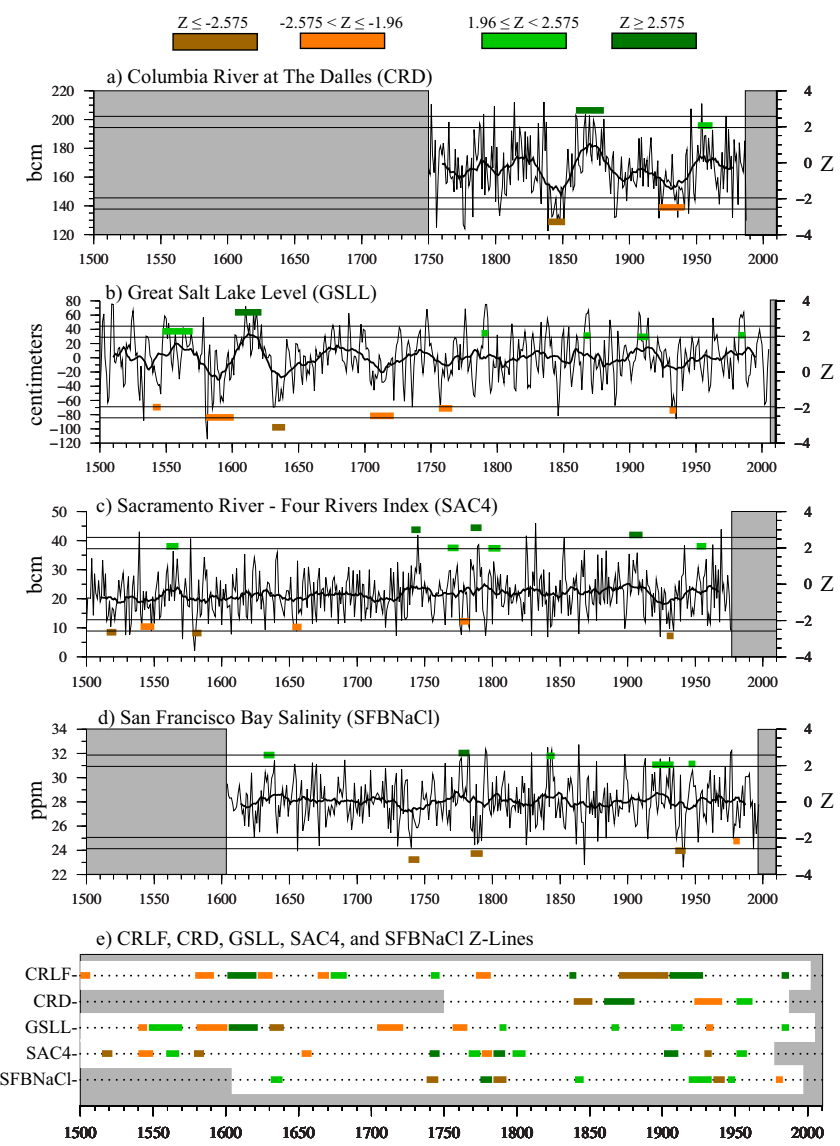

Figure 3. (a) As in Fig. 2e for the reconstructed flow of the Columbia River at The Dalles during 1750-1987. (b) As in Fig. 2e for the reconstructed level of the Great Salt Lake during 15002005. (c) As in Fig. 2e for the reconstructed Sacramento RiverFour Rivers index during 1500-1977. (d) As in Fig. 2e for reconstructed San Francisco Bay salinity during 1604-1997. (c) The optimal ranking regimes in Figs. $2 \mathrm{e}$ and (a-d) plotted as $Z$-lines. The significance shading scheme for $Z$ statistics is as shown at the top.

riod that does not overlap with all previously recorded periods, and continues until all the significant ranking regimes identified by the 95 running tests have been tested. In the CRLF series the most significant sequence of low-flow years occurred during 1870-1904 ( $Z=-2.742)$. While the $Z$ normalization process allows for comparing the significance of $Z$ statistics derived using varying sample sizes, it also makes it possible to rank the optimal ranking regimes found in a reconstruction series. As a time series' ORR $Z$ statistics can be interpreted as measures of regime intensity, the most intense CRLF pluvial and drought periods in Fig. 2e occurred during 1601-1621 and 1870-1904.

Figure $3 \mathrm{a}-\mathrm{d}$ show the results of the ORR analysis when applied to the reconstructions of (a) Columbia River flow at The Dalles, (b) the level of the Great Salt Lake, (c) the Sacramento River-Four Rivers index (Meko et al., 2001), and, (d), San Francisco Bay salinity. Because the method defines non-overlapping high- and low-ranking regimes at two significance levels, compact graphs can be formed showing the ORR results from multiple time series. Using Fig. 2b's shading scheme for positive and negative significance, a time series' optimal ranking regimes can be graphed on a single horizontal line referred to as a $Z$-line. The optimally significant streamflow, lake level, and salinity regimes from Figs. 2e and 3a-d have been re-plotted as Z-lines in Fig. 3e. By applying the ORR algorithm to all of Table 1's reconstructions, the resulting $Z$-lines can be similarly arranged to show hydrological regime patterns over all of Fig. 1's corresponding locations.

\section{ORR analyses of hydroclimate reconstructions: 1500-2007}

Figure 4 shows the $Z$-lines for Table 1's 57 reconstructions during 1500-2007. The white areas in that figure show each reconstruction's duration during that period, and each $Z$ line's vertical coordinate is determined by the corresponding reconstruction number in Table 1 and Fig. 1. These $Z$-lines will be referred to by their Table 1 reconstruction number, i.e., R1, R2,... R57. The $y$ axis color backgrounds of Fig. 4's reconstruction numbers also follow Fig. 1's state color shading scheme. Thus R1-R14 are located in Fig. 1's light yellow states, R15-R47 are located in Utah and Colorado, R48R53 in New Mexico and Arizona, while R54-R57 are located in California. In the following, the timing and duration of Fig. 4's drought and pluvial regimes will be compared with those highlighted in previous work, particularly Fye et al. (2003), Stahle and Dean (2011), and Cook et al. (2007), which were based on the summer Palmer Drought Severity Index (PDSI) reconstructions of Cook et al. (1996, 1999, 2004, 2007).

\subsection{6th and 17th centuries}

Figure 4a outlines dry ORR periods beginning in the 1570s and ending on or before 1601 . These periods coincide with the late 16th century "megadrought" apparent in streamflow and PDSI reconstructions (Meko et al., 1995; Stahle et al., 2000, 2007), which Meko et al. (1995) and Stahle et al. (2007) describe as occurring during 1579-1598 and 1559-1582 respectively. Stahle and Dean (2011) describe this period as ".... the most severe sustained North American drought evident in the tree-ring record for the past 500 years". In the ORR analysis of the Fig. 2e CRLF reconstruction, this drought's effects are apparent as a low-flow regime during 1579-1592. However, as measured by that 14-year period's $Z$ statistic (Table 2), that dry regime is the second most intense in the Meko et al. (2007) CRLF reconstruction during 1500-2005.

Following the late 16th century drought was a multidecadal wet period during the early 17 th century (Fig. 4b). This drought-to-pluvial transition is clearly seen in the level 

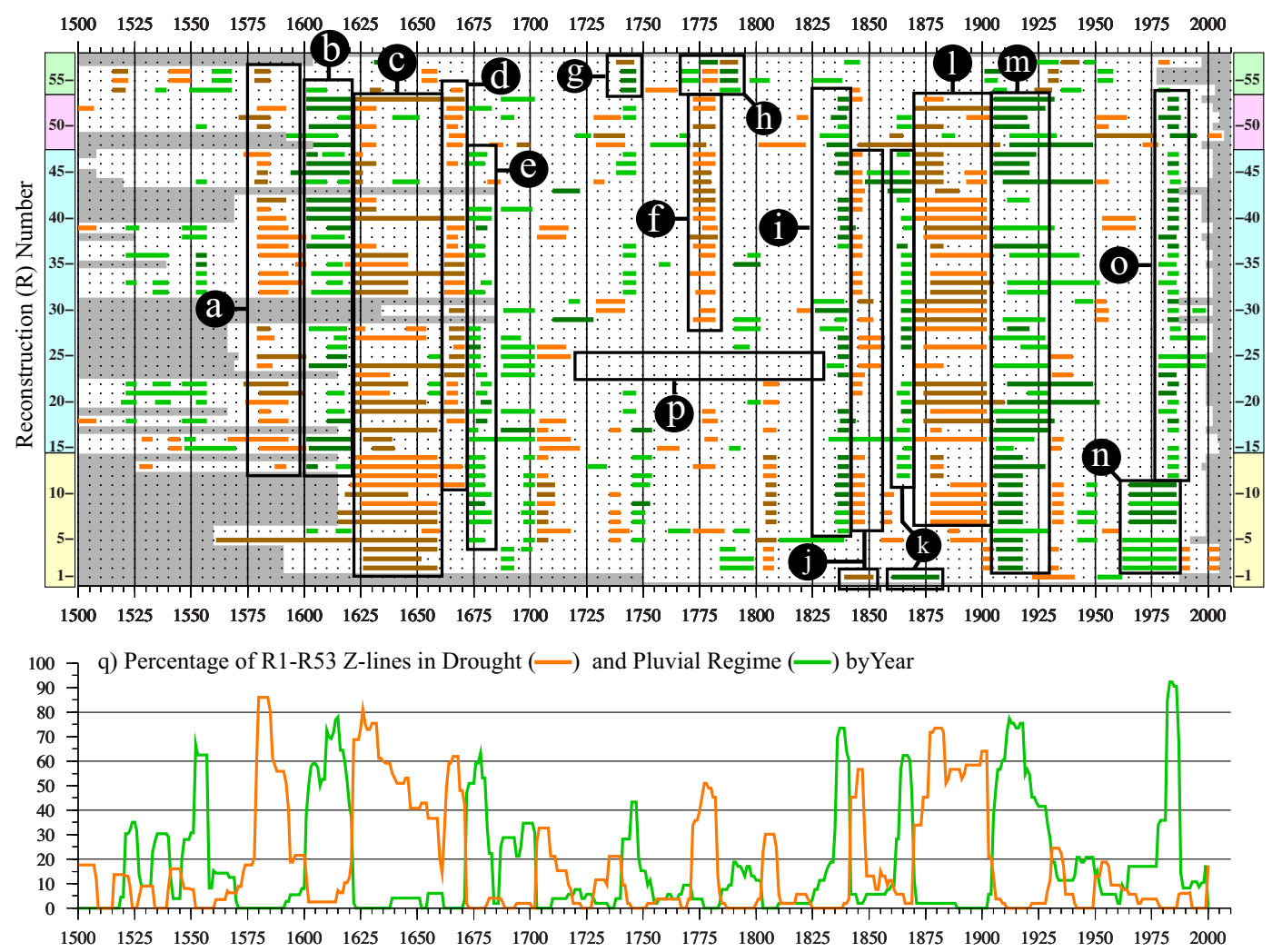

Figure 4. Z-lines for the optimal ranking regimes found in each of the Table 1 reconstructions. The vertical axis marks the corresponding reconstruction number as found in Table 1 . The vertical axis' yellow, cyan, violet, and green shaded regions mark $Z$-lines from reconstructions in the similarly shaded states in Fig. 1. Positive and negative significance at $95 \%$ and $99 \%$ confidence levels is marked by the shading scheme at the top of Fig. 3. The (a-p) black rectangles outline regime features discussed in the text. (q) The percentage of R1-R53 Z-lines that indicate significant drought or pluvial conditions $(|Z| \geq 1.96)$ during $1500-2000$. Green traces indicate the percentage of lines in a pluvial regime, and orange traces show the percentage of lines in a drought regime during each year.

Table 2. Periods, durations, and Mann Whitney $Z$ statistics of the five wettest and driest ranking regimes in the ORR analysis of the Meko et al. (2007) reconstruction of Colorado River flow at Lees Ferry annual flow during 1500-2005. Bold duration numbers mark the longest wet and dry regime periods.

\begin{tabular}{llrrlrr}
\hline$|Z|$ Rank & Period & Duration & $Z$ & Period & Duration & $Z$ \\
\hline 1 & $1601-1621$ & 21 & 3.498 & $1870-1904$ & $\mathbf{3 5}$ & -2.742 \\
2 & $1982-1987 / 1836-1841$ & 6 & 3.063 & $1579-1592$ & 14 & -2.419 \\
3 & $1905-1928$ & $\mathbf{2 4}$ & 2.804 & $1772-1782$ & 11 & -2.332 \\
4 & $1672-1683$ & 12 & 2.530 & $1663-1671$ & 9 & -2.209 \\
5 & $1741-1747$ & 7 & 1.966 & $1622-1632$ & 11 & -2.192 \\
& & Wet periods & & \multicolumn{3}{c}{ Dry periods } \\
\hline
\end{tabular}

of the Great Salt Lake reconstruction (Fig. 3b, R15), and clearly significant wet regimes are also found in the upper Rio Grande (R50) and both CRLF reconstructions (R52, R53) during this time. Based on an analysis of gridded PDSI reconstructions, Fye et al. (2003) also note a western US pluvial period during 1602-1622. The earliest onset year in Fig. 4b's optimally wet periods is 1601 , while the latest termination year is 1622 .
After 1621 dry periods re-appear in many proxy records that showed drought conditions during the late 16th century (Fig. 4c). In some instances these dry regimes are of longer duration and higher significance than the same reconstruction's previous dry periods in Fig. 4a, e.g., those in Fig. 4c's R19, R24, R32-R36, and R40 reconstructions. Figure 4c's multi-decadal drought pattern tends to be more consistent in the R2-R14 eastern Idaho and Wyoming streamflow reconstructions. Fye et al. (2003) note drought conditions over this 
area during 1624-1633, but the Fig. 4c low-flow regimes are of generally longer duration.

In Fig. 4d brief drought periods are detected after many of the Fig. $4 \mathrm{c}$ dry regimes. However, it is unclear whether these are two distinct drought events as some extended regimes span both periods. The Woodhouse et al. (2006) CRLF reconstruction (R53) contains a 50-year dry ORR period during 1622-1671 that is the longest and most significant low-flow regime in that record (Table 3). Dry regimes of similar duration and significance are found in the Colorado River at Hot Sulphur Springs (R19), Big Thompson (R24), Blue River at Dillon (R34), and Colorado River near Cisco (R40) reconstructions in Fig. 4c and d. The duration of Fig. 4d's dry regimes coincides with the 1666-1671 Pueblo drought period (Cook et al., 2007; Stahle and Dean, 2011), which is also noted by Fye et al. (2003) as occurring during 1663-1672. The earliest onset year of the Pueblo Drought regimes detected here is 1662 , while the latest termination year is 1672 . After 1671 brief wet regimes, most ending in 1683 or before, are found in many of the reconstructions (Fig. 4e).

\subsection{8th century}

Compared to the $1575-1683$ period in Fig. $4,1700-1825$ is marked by the relative absence of consistent drought or pluvial patterns. One exception is Fig. 4f's pattern of dry periods evident over the upper Colorado and upper Rio Grande watersheds (i.e., R36-R48, R50, R52, R53) during the 1770s and early 1780s. Many of these ORR periods, including those in the two CRLF reconstructions (R52, R53), coincide with the 1772-1782 time window attributed to this drought by Fye et al. (2003). Figure 4f's drought periods immediately preceded the Año del Hambre ("Year of Hunger") drought that affected northern Mexico and the southern Great Plains during 1785-1787 (Stahle and Dean, 2011). Although the 18th century appears to be relatively free of extended drought or pluvial regimes over the Fig. 1 watershed regions, this period may not have been generally drought-free over western North America. Before the Año del Hambre period and the drought regimes of Fig. 4f, a series of indigenous rebellions have been associated with drought conditions in northern Mexico during 1725-1742 (Brenneman, 2009).

Fresh water inflow to San Francisco Bay from the Sacramento-San Joaquin Delta has a controlling influence on the bay's salinity levels (Stahle et al., 2001). In the mid-18th century the California reconstructions (R54-R57) show a semi-consistent pattern of wet (dry) streamflow regimes that coincide with fresh (salty) San Francisco Bay salinity (SF$\mathrm{BNaCl}$ ) regimes. During 1740-1747 high-flow periods are found in the Feather River (R55) and Sacramento River-Four Rivers (R56) reconstructions, while a significant incidence of fresh, low-ranked, SFBNaCl values (R57) are detected during 1738-1746 (Fig. 4g). In the 1770s these regimes reverse sign, with low streamflow periods indicated in the Feather River and Sacramento River-Four Rivers records during
1776-1783, while a salty SFBNaCl regime is detected during 1775-1783 (Fig. 4h). Immediately after that period in Fig. 4h a fresh SFBNaCl regime occurs during 1784-1792, while the Sacramento River-Four Rivers and Feather River reconstructions show high-flow periods during that same time. Although the Salinas River at Paso Robles (R54) does not flow into San Francisco Bay, its $Z$-line also shows consistent periods of low and high flow with the Feather River and Sacramento River-Four Rivers flow regimes in Figs. $4 \mathrm{~g}$ and $\mathrm{h}$.

\subsection{9th century}

After 1825, pluvial conditions are widely apparent outside of California and the most northern streamflow reconstructions (R1-R5), with the years 1836-1841 indicated as the most common wet ORR period (Fig. 4i). Both Stahle and Dean (2011) and Fye et al. (2003) consider this pluvial to have occurred during 1825-1840, and the significant ranking regimes in Fig. 2d's CRLF series during that time also indicates significant wet periods beginning in the late 1820 s over the upper Colorado watershed. However, Fig. 4i's ORR results suggest that the most significant concentrations of wet years occurred after 1835. This wet period was followed by dry regimes in the early 1840 s (Fig. $4 \mathrm{j}$ ). Woodhouse et al. (2002) attribute this drought to $1845-1856$ based on an analysis of 60 tree-ring chronologies from the Rocky Mountains, the Colorado Front Range, and the Great Plains. Stahle and Dean (2011) assign this dry period to 1841-1865, and consider it the longest and most severe reconstructed drought over the Great Plains and western North America during the 19th century. In Fig. 4i the most common dry ORR periods occur during 1842-1847 and 1842-1848, and are generally not highly significant, i.e., at a $99 \%$ confidence level. During this time, however, the reconstructed flow for the Columbia River at The Dalles (R1, Fig. 3a) does show a highly significant sequence $(Z=-3.309)$ of low-flow conditions during 1839-1852. After the low-flow ORR periods of Fig. 4j, Fig. $4 \mathrm{k}$ outlines a consistent pattern of brief (6-8-year) wet periods that, for the most part, begin after 1861 and end before 1871. The most common high-flow period is 18641869 , which coincides closely with the 1867-1869 "Garden Myth" wet period over the western USA described by Cook et al. (2007). Although Cook et al. (2007) note a second wet episode over the western USA during 1877-1879, that wetness was not found in the reconstructed summer PDSI over the WY-UT-CO region (their Fig. 13). A shift to wet conditions is also found in the reconstructed Columbia River flow during this time (Fig. 3a), although, unlike Fig. 4j's dry periods, the 1860-1881 Columbia high-flow period is generally more significant $(Z=2.916)$ and spans both "Garden Myth" periods.

After 1869, dry regimes, many of multi-decadal duration, are apparent over most of the R7-R53 reconstructions (Fig. 41). Between 1870 and the early 20th century Fye et al. (2003) note separate southwestern US drought periods 
Table 3. Periods, durations, and Mann-Whitney $Z$ statistics of the five wettest and driest ranking regimes in the ORR analysis of the Woodhouse et al. (2006) reconstruction of Colorado River flow at Lees Ferry annual flow during 1500-1997. Bold duration numbers mark the longest wet and dry regime periods.

\begin{tabular}{llrrlrr}
\hline$|Z|$ Rank & Period & Duration & $Z$ & Period & Duration & $Z$ \\
\hline 1 & $1601-1621$ & 21 & 3.496 & $1622-1671$ & $\mathbf{5 0}$ & -2.695 \\
2 & $1836-1841$ & 6 & 3.230 & $1772-1782$ & 11 & -2.441 \\
3 & $1982-1987$ & 6 & 3.036 & $1874-1883$ & 10 & -2.171 \\
4 & $1905-1932$ & $\mathbf{2 8}$ & 2.647 & $1842-1847$ & 6 & -1.980 \\
5 & $1687-1702$ & 16 & 2.486 & $1528-1533$ & 6 & -1.902 \\
\multicolumn{2}{c}{ Wet periods } & \multicolumn{5}{c}{ Dry periods } \\
\hline
\end{tabular}

during 1870-1883 and 1897-1904, while Stockton and Jacoby (1976) note a single extended period of low flow in their CRLF reconstruction during 1870-1894. The 18701904 low-flow regime in the Meko et al. (2007) CRLF reconstruction (R52) is the longest ORR of either sign in that record, and also its most significant ORR dry period $(Z=$ -2.742) since 1500 (Table 2). However, a low-flow period during 1874-1883 in the Woodhouse et al. (2006) CRLF reconstruction (R53) has a shorter duration and is only the third most significant dry regime during that time (Table 3). Other reconstructions that show multi-decadal dry regimes significant at a $99 \%$ confidence level in Fig. 41 include R18, R20R22, R29, R31-R33, and R39.

\subsection{0th century}

Figure $4 \mathrm{~m}$ outlines early 20 th century high-flow conditions apparent in most of the reconstructions apart from the California (R54-R57) and Columbia River flow (R1) records. The most common beginning year in these wet periods is 1905, and most end on or before 1934. Wet periods in six reconstructions, however, persist into the 1940s and early 1950s (R20, R22, R33, R36, R44, and R48). Fye et al. (2003) and Stahle and Dean (2011) define this pluvial's duration as 1905-1917 and 1907-1916, respectively based on their analyses of reconstructed summer PDSI. These high-flow periods are most consistently and significantly detected in gauge stations in Idaho and Wyoming (R2-R20), and in southern Colorado, New Mexico, and Arizona (R44-R53), but are not as clearly apparent in the reconstructions for upper Colorado and upper South Platte gauge stations in northern Colorado (R21-R52).

Despite the relative lack of significant wet regimes in the upper Colorado watershed in Fig. 4m, wet periods are detected in the Meko et al. (2007) CRLF reconstruction (R52) during 1905-1928 and in the Woodhouse et al. (2006) CRLF reconstruction (R53) during 1905-1932. Stockton and Jacoby (1976) identified a Colorado River high-flow period during 1906-1930, and cited it as the longest and greatest period of anomalously high flow in their 1512-1961 CRLF reconstruction. However, the highest magnitude positive ORR $Z$ statistic in both the Meko et al. (Table 2) and Woodhouse et al., CRLF reconstructions (Table 3) occur during 1601-1621. Although the 1905-1928 and 1905-1932 wet periods are the longest in those reconstructions, the corresponding $Z$ statistics rank third (Table 2) and fourth (Table 3 ) respectively.

Figure 4 shows little evidence of the effects of the 1930s drought, which were mainly centered over the Great Plains in the analyses of Shubert et al. (2004) and Mauget (2003a). In the analysis of Fye et al. (2003) drought conditions during 1929-1940 also extend into parts of the Columbia River watershed. A 1922-1941 low-flow regime in the Columbia River reconstruction (R1, Fig. 3a) overlaps with the Fye et al. (2003) drought period, but also precedes it. Unlike the drought of the 1930s, the 1950s drought had strong precipitation effects over Colorado and New Mexico during 1950 1956 (Mauget 2003a). However, apart from early 1950s lowflow regimes in R29-R31, R44, and R50, there is also no widespread evidence of that drought's effects in the Fig. 4 reconstructions.

In Fig. 4n a pattern of high-flow regimes beginning in the mid-1960s and ending in the mid-1980s is evident in the Idaho and Wyoming reconstructions (R2-R5, R7-R11). One of Fig. 4's most consistent patterns of pluvial regimes is found in R12-R53 in the mid 1980s (Fig. 4o). Woodhouse and Lukas (2006a) refer to a period of unusually abundant moisture in Colorado during 1982-1999, but in Fig. 4o's flow reconstructions, the most common wet ORR period is 19821987. Although most of the Fig. 4 reconstructions end during or before the 1999-2004 drought period in the western USA (Piechota et al., 2004; Cook et al., 2007), R2-R4 and R49 show low-flow ORR periods during 2000-2005 and 20002006.

\subsection{Centennial-scale variation}

Apart from the four California reconstructions (R54-R57), Fig. 4's dominant variability patterns are evident as alternating drought-pluvial regimes during the late 16th and 17th centuries (Fig. 4a-e) and also during the 19th and early 20th centuries (Fig. 4i-m). However, between those two periods, with the exception of low-flow conditions in R29-R53 during the 1770s (Fig. 4f), many of the reconstructions are more consistent with red noise during 1680-1835. An example of 
this lack of significant IMD variation is seen in the R23R25 reconstructions, which have no ranking regimes significant at a $95 \%$ confidence level during 1719-1830 (Fig. 4p). These periods of active and dormant hydroclimate variability are more evident when the number of $Z$-lines that are in significant $(|Z| \geq 1.96)$ drought and pluvial regimes are counted for each year of 1500-2000. In Fig. 4q these counts are expressed as percentages of the total number of R1-R53 $Z$-lines that are defined in a particular year, which is determined by the duration of the reconstruction records. As few lines extend past the year 2000, the Fig. 4q percentages are not calculated during 2001-2007. During 15801680 and $1835-1930$ relatively high percentages $(>40 \%)$ of the R1-R53 Z-lines experienced alternating wet and dry IMD regimes. However, between those two periods, years in which more than $40 \%$ of the reconstructions are in a drought or pluvial ORR period are relatively rare. As a result, the Fig. 4 ORR analyses generally show two active centennial-scale periods marked by alternating IMD wet and dry regimes, separated by a period during the 18th and early 19 th century with relatively little IMD regime variation. Similar centennial-scale variability in the Cook et al. (1999) summer PDSI reconstructions was noted over western US grid locations by Hidalgo (2004). That analysis calculated the percentage of the PDSI total power spectral density in bidecadal (8-32 year) and penta-decadal (32-64 year) frequency bands during three periods: 1525-1650, 1700-1825, and 1850-1975. Penta-decadal PDSI variation was dominant during the $1525-1650$ and $1850-1975$ periods over grid locations in the interior west, but virtually absent during 1700 1825 (Hidalgo, 2004; his Fig. 3d, e, f). Conversely, higher frequency bidecadal PDSI variation was relatively strong during 1700-1825, but less apparent during the 1525-1650 and 1850-1975 periods (Hidalgo, 2004; his Fig. 3a, b, c).

Decadal to multi-decadal variation in US hydroclimate has been associated with similarly persistent regimes in North Pacific and North Atlantic sea-surface temperature; i.e., those associated with the Pacific Decadal Oscillation (PDO) and the Atlantic Multidecadal Oscillation (AMO), and with regimes in the El Niño-Southern Oscillation (ENSO) mechanism (see review in McCabe and Wolock, 2013). Oceanic forcing is generally thought to play a central role in sustaining persistent climate regimes (Schubert et al., 2004, 2008; Cook et al., 2007; Solomon et al., 2010; Hoerling et al., 2011). Over the interior western USA the combined influence of the AMO and PDO are considered to be particularly important (Gray et al., 2003; Hidalgo 2004; McCabe et al., 2004, 2007). As a result, Fig. 4q's patterns of relatively active and inactive periods of IMD variation lead to questions as to whether similar variation is evident in PDO, AMO, and ENSO reconstructions. A commonly studied influence over the western USA is the PDO, which has been associated with pre-instrumental precipitation regimes in PDO reconstructions derived from tree-ring chronologies (Gedalof and Smith, 2001; Biondi et al., 2001; MacDonald and Case,
2005). However, as Mantua and Hare (2002) and D'Arrigo and Wilson (2006) note, the variation in these PDO reconstructions are frequently inconsistent. This lack of consensus was also found here in the ORR analyses of four PDO reconstructions (Appendix A). Moreover, the $Z$-lines for those reconstructions, and for reconstructions of the AMO and a unified ENSO proxy series, show no obvious similarity to Fig. 4q's centennial-scale pattern of active and inactive IMD variation (Fig. A2 in Appendix). As a result, even though those consistent patterns of drought and pluvial activity suggest an oceanic influence, the ORR analyses of Appendix A's reconstructed North Pacific and North Atlantic climate indices show no clear evidence of that influence.

\section{Summary and discussion}

The optimal ranking regime (ORR) method was used to identify intra- to multi-decadal (IMD) variation in reconstructed records of western US streamflow, the level of the Great Salt Lake (Fig. 3b), and San Francisco Bay salinity levels (Fig. 3d) during 1500-2007. The ORR algorithm, which is described in Sect. 3 and demonstrated in Fig. 2a-e, detects the most significant sequences of low- and high-ranked values in a time series relative to a null hypothesis that holds that the series consists of trend-less red noise. As these optimal ranking sequences are defined over non-overlapping 6-100year time windows, the associated periods of low and high rankings in a reconstruction series, and their significance at 95 and $99 \%$ confidence levels, can be displayed on graphically concise horizontal traces referred to as $Z$-lines (Figs. 3e and 4).

As described in Sect. 3, Mann-Whitney $U$ statistics for samples of rankings are normally distributed, with values in a $U$ distribution's lower and upper tails indicating a sample with a high incidence of low or high rankings. In the ORR procedure $U$ statistics calculated over running sampling windows are normalized into $Z$ statistics (Eqs. 3, 4), which allows for determining the significance of each running sample. Because these running analyses are repeated with varying sample sizes, this normalization also allows for comparing the significance of $Z$ statistics derived using each sample size. The optimal ranking regimes detected by this "bruteforce" algorithm are the most significant ranking sequences in all the running analyses that occur over non-overlapping time windows (e.g., Fig. 2e). Because each ORR's $Z$ statistic is a measure of the regime's concentration of extreme low or high rankings, those statistics can also be used to rank the intensity of a reconstruction's leading drought and pluvial regimes. However, because Eq. (4)'s $\mu_{1}$ and $\sigma_{1}$ null parameters are calculated via a Monte Carlo (MC) process that uses random number generators, the magnitudes of ORR $Z$ statistics can vary slightly between successive applications of the algorithm. This is primarily due to variation in the $\sigma_{1}$ param- 
eter, which can lead to slight variation in the magnitudes of $Z$ statistics in separate runs of the algorithm.

In Tables 2 and 3 the five wettest and driest flow regime periods were defined for the Meko et al. (2007) and Woodhouse et al. (2006) reconstructions of Colorado River at Lees Ferry (CRLF) flow based on the $Z$ statistics of their optimal ranking regimes. In addition, the longest high- and lowflow periods were highlighted. When those ORR analyses are repeated twice with different MC simulations, the leading regime's $Z$ magnitudes vary slightly from the Tables 2 and 3 values, but the ordering of the wettest and driest regimes, and the longest duration periods, are unchanged (Appendix B). As a result, those rankings, and the relative intensity of reconstructed low- and high-CRLF-flow regimes, appear insensitive to variation in the $\sigma_{1}$ parameter from different MC simulations. Although Stockton and Jacoby (1976) identified $1906-1930$ as the leading period of high flow in their 450-year CRLF reconstruction, the most significant sequence of rankings found here in the Meko et al. and Woodhouse et al. CRLF reconstructions occurred during 1601-1621. In other cases the intensity of ORR drought periods over the interior western USA detected here seems inconsistent with previous analyses based on reconstructed summer PDSI. Although Goodrich (2007) and Stahle and Dean (2011) cite the late 16th century drought (Fig. 4a) as the most severe North American drought evident in the tree-ring record during the past 500 years, the drought regimes in the $Z$-lines outlined in Fig. 4c and d during the 17th century appear stronger in both duration and intensity over the WY-UT-CO region. In the Woodhouse et al., CRLF reconstruction the driest ORR period occurred during 1622-1671 (Table 3). Stahle and Dean (2011) cite 1841-1865 as the most severe drought over the Great Plains and western North America during the 19th century based on reconstructed PDSI analyses, yet that period shows relatively weak evidence of dry regimes in Fig. 4 j. Based on the magnitudes of ORR $Z$ statistics, a more intense 19th century drought over the upper Colorado watershed is indicated here during 1870-1904 in Fig. 4l, which is also the Meko et al., CRLF reconstruction's driest period (Fig. 2e, Table 2).

For the most part, the ORR analyses conducted here were of streamflow reconstructions from the TreeFlow web data resource (http:/treeflow.info). As described in Sect. 4.4 and summarized in Fig. 4q, a common pattern in these analyses is that of IMD cycles of drought and pluvial regimes during the late 16th and 17th centuries (Fig. 4a-e), a period with relatively little variability during the 18th century, and the reappearance of alternating drought and pluvial periods during the 19th and early 20th centuries (Fig. 4i-m). Although studies summarizing reconstructed US hydroclimate tend to emphasize extended drought (e.g., Meko et al., 1995; Woodhouse and Overpeck, 1998; Cook et al., 1999, 2007; Cole et al., 2002), less attention is generally paid to pluvial periods (Woodhouse et al., 2005). However, over the interior western USA the results here indicate two centennial-scale periods marked by drought-pluvial cycles, separated by an 18 th century period that was, in a climatic sense, comparatively quiet.

Although Fig. 4's individual ORR analyses of reconstructed streamflow show consistent drought and pluvial regimes, the Table 1 streamflow reconstructions may not be completely independent. As many of these reconstructions were done by individual groups (e.g., Barnett et al., 2010; Wise, 2010) and are from adjacent watersheds, some may reflect flow variability estimated from overlapping sets of dendrochronologies. As noted in Sect. 2, a number of the Table 1 reconstructions are for flow for the same rivers at various points in their watershed. Also, because these reconstructions are mostly representative of the upper Colorado watershed and the WY-UT-CO region (Table 1, Fig. 1), Fig. 4's overall regime pattern may not represent variability over the broader western USA. Whether this is the case might be resolved in the future via an ORR analysis of the more spatially continuous Cook et al. (2007) PDSI reconstructions.

However, over the upper Colorado region, the consistency of Fig. 4's reconstructed flow regime patterns does suggest a real signal in centennial-scale hydroclimate. Given the current conception of the role of oceanic mechanisms in driving the IMD hydrology of the upper Colorado River basin (McCabe et al., 2007) and the western USA in general (Redmond and Koch, 1991; Cayan et al., 1998; Dai, 2013), this leads to questions as to whether those mechanisms may also experience centennial-scale periods of active and dormant variability. As described in Sect. 4.5, such variation has been noted by Hidalgo (2004) in reconstructed summer PDSI over the western USA. The leading modes of the Hidalgo (2004) rotated principal component analysis of the Cook et al. (1999) summer PDSI reconstructions show common features with the Biondi et al. (2001) PDO reconstruction and the AMO reconstruction of Gray et al. (2004). As a result, he concluded that extended droughts over the interior western USA may be a consequence of combined PDO and AMO effects. However, the ORR analyses of four independently derived PDO reconstructions in Fig. A1c-f, which includes the Biondi et al. (2001) reconstruction (PDO-B), show no common regime features. Appendix A's ORR analyses of a unified ENSO proxy series and of North Atlantic sea-surface temperature anomalies also show no evidence of regime patterns similar to that of Fig. 4q. However, this may not indicate that Fig. 4q's centennial-scale signal in reconstructed streamflow occurred independently of oceanic variability. The lack of common regime patterns in the ORR analyses of the Appendix A PDO reconstructions suggests that Pacific decadal variation during the pre-instrumental period is, at this time, essentially unknown. However, the ORR method might be used to indirectly detect that variability. The current approach of inferring the state of the pre-instrumental PDO typically involves comparing tree ring or coral chronologies with observed PDO (Gedalof and Smith, 2001; Biondi et al., 2001; MacDonald and Case, 2005) or North Pacific Index (D'Arrigo et al., 2005) data to develop regression models. 
An alternative approach might involve applying ORR analysis to networks of streamflow or temperature reconstructions around the Pacific Basin, e.g., TreeFlow data counterparts in Asia or South America. Consistent regime patterns from ORR analyses of dense networks of Asian and North American reconstructions, or from a transect of reconstructions spanning the western coasts of North and South America (e.g., Villalba et al., 2001, 2011), might indirectly show a common low-frequency Pacific influence.

The ORR method may be a useful option for evaluating IMD variability in reconstructed climate records. Because it is based on the analysis of data rankings, it is insensitive to the influence of data outliers and to how data is distributed. The method does not involve the use of subjectively selected thresholds or filters to detect low-frequency variation, but instead uses an exhaustive and relatively objective algorithm to find the most significant ranking regimes occurring over a range of IMD timescales. The graphic approach to displaying $Z$-lines demonstrated here in Figs. 3e and 4 can help to identify consistent regime patterns in numerous reconstructions, and to corroborate variability in reconstructions produced by different investigators using different methods. These features may make the method particularly useful in evaluating the extensive data sets being generated in millennialscale regional temperature reconstructions (PAGES $2 \mathrm{k}$ Consortium, 2013). The $Z$-line diagrams may also highlight climate regimes that appear as outliers relative to those in other data records. Examples in Fig. 4 of such possible behavior are the 99-year low-flow regime in the Wind River (R5) reconstruction during 1561-1659, and the 64-year dry regime in the Canadian River Z-line (R48) during 1845-1908. However, some features of the ORR method may also lead users to consider more traditional methods such as runs analysis (Dracup, 1980). Because of its use of Monte Carlo simulated null parameters, attempts at ranking the intensity and duration of optimal regime periods in a reconstruction series, e.g., as in the CRLF reconstructions in Tables 2 and 3, may require repeated applications of the algorithm to verify rank ordering. It is also possible that runs analysis may be more useful to water managers who need estimates of the probability of a drought or pluvial period of a specified duration (e.g., Biondi 2002, 2005). 
Appendix A: ORR analyses of Pacific and North Atlantic climate indices

As in Fig. 2e, Fig. A1a-f show the results of ORR analyses of six reconstructions of North Atlantic and Pacific climate variability during 1500-1998. Table A1 summarizes the first and last years of the reconstructions, their calibration periods where applicable, and references. As these reconstructions follow variation in sea-surface temperature anomalies (SSTA), optimal ranking regimes significant at 95 and $99 \%$ confidence levels are marked in Figs. A1 and A2 with the warm shade-cool shade significance scheme shown at the top of Fig. A1. Thus in the analyses of North Atlantic sea-surface temperatures anomalies (NATSSTA) and a Unified ENSO Proxy (UEP) series red (blue) shades indicate anomalously warm (cool) SSTA regimes over the North Atlantic and equatorial Pacific. In the Pacific Decadal Oscillation (PDO) analyses red (blue) shades mark warm (cool) SSTA periods in the Gulf of Alaska and along the western coast of North America.

Table A1. Reconstruction periods, calibration periods, and references for the North Atlantic SSTA (NATSSTA), Unified ENSO Proxy (UEP) and PDO-B, -D, -M, and $-\mathrm{S}$ reconstructions of Fig. A1a-f.

\begin{tabular}{llll}
\hline & $\begin{array}{l}\text { Reconstruction } \\
\text { Period }\end{array}$ & $\begin{array}{l}\text { Calibration } \\
\text { Period }\end{array}$ & Reference \\
\hline NATSSTA & $1567-1990$ & $1922-1990$ & Gray et al. (2004) \\
UEP & $1650-1977$ & NA & McGregor et al. (2010) \\
PDO-B & $1661-1991$ & $1962-1991 /$ & Biondi et al. (2001) \\
& & $1925-1954$ & \\
PDO-D & $1565-1988$ & $1917-1960$ & D'Arrigo and Wilson (2006) \\
PDO-M & $993-1996$ & $1940-1996$ & MacDonald and Case (2005) \\
PDO-S & $1470-1998$ & $1925-1998$ & Shen et al. (2006) \\
\hline
\end{tabular}

Figure A1a shows IMD regimes of cold and warm NATSSTA conditions derived from the reconstructions of Gray et al. (2004). Figure A1b shows the ORR analysis of the UEP series of McGregor et al. (2010). The UEP series is the leading principal component of a principle component analysis of 10 reconstructions that reflect ENSO variation, and is considered to represent those series' common ENSO signal during 1650-1977. As the low-passed UEP series shows IMD variability similar to that of the Pacific Decadal Oscillation (PDO) during the 20th century, McGregor et al. (2010) also consider it as a potential PDO proxy.

Figure A1c-f shows the ORR analyses of four PDO reconstructions. The PDO-B (Fig. A1c) series is the reconstruction of Biondi et al. (2001), which was based on southern California and northern Baja California tree-ring records and reconstructs November-March PDO variation between 1661 and 1991. The PDO-D (Fig. A1d) series is the D'Arrigo and Wilson (2006) reconstruction of boreal spring (March-May) PDO during 1565-1988 based on Asian and Siberian treering records. The PDO-M (Fig. A1e) reconstruction of Mac-
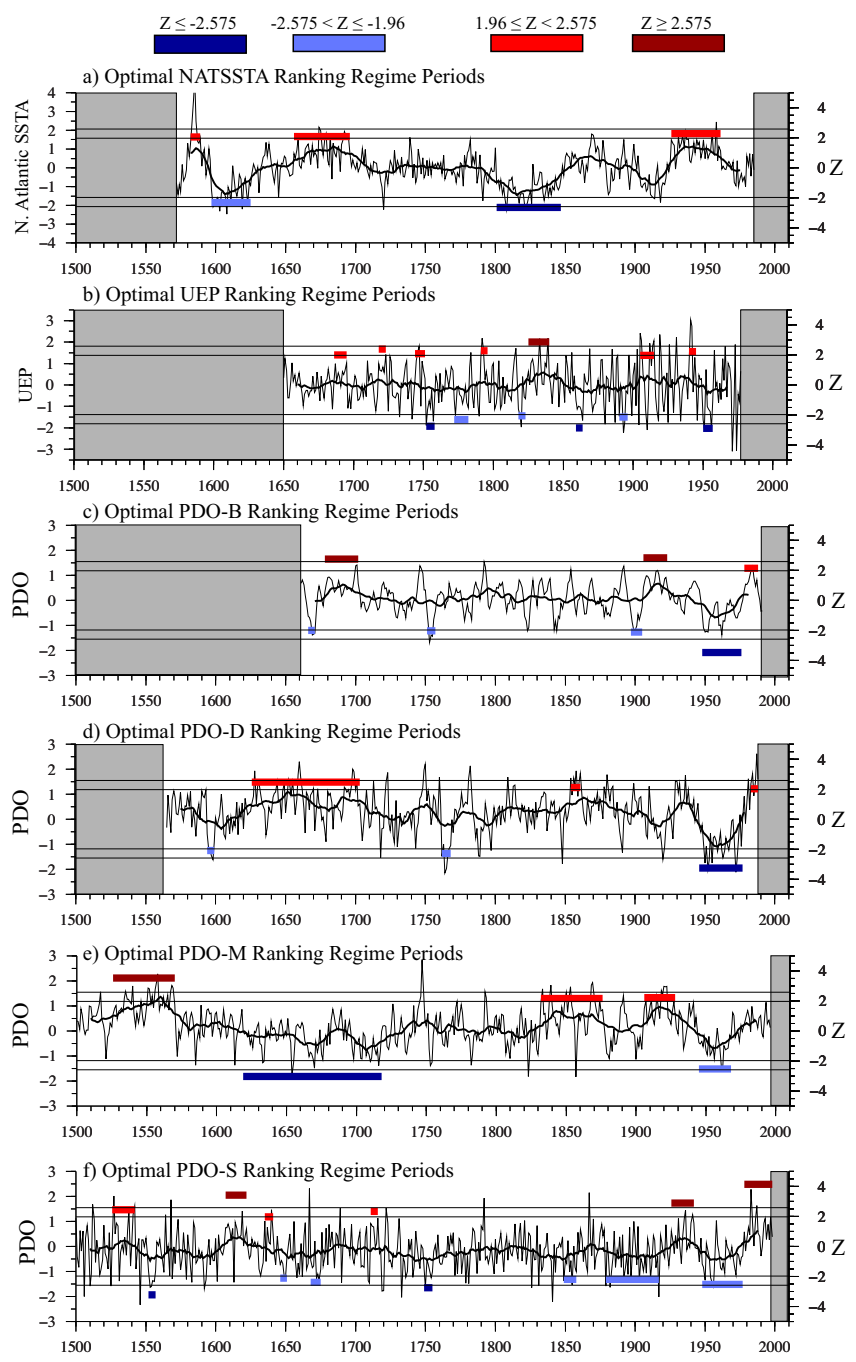

Figure A1. (a) Optimal ranking regime analysis of the North Atlantic SSTA reconstruction of Gray et al. (2004). (b) As in (a) for the Unified ENSO Proxy of McGregor et al. (2010). (c) As in (a) for the PDO reconstruction of Biondi et al. (2001). (d) As in (a) for the PDO reconstruction of D'Arrigo and Wilson (2006). (e) As in (a) for the PDO reconstruction of MacDonald and Case (2005). (f) As in (a) for the PDO reconstruction of Shen et al. (2006).

Donald and Case (2005) was based on California and Alberta tree-ring records. The PDO-M values reconstruct annual (January-December) PDO during 993-1996, but only the 1500-1996 values were tested in the Fig. A1e ORR analysis. The PDO-S (Fig. A1f) series is the Shen et al. (2006) reconstruction of annual PDO during 1470-1998 based on a summer drought/flood index derived from Chinese historical documents. Like the PDO-M analysis, only the 1500-1998 PDO-S values were subjected to ORR analysis in Fig. A1f.

Figure A2 shows the $Z$-lines for the NATSSTA, UEP, and PDO-B, -D, -M, and -S ORR analyses, and compares those regime periods with the variation in R1-R57 streamflow regimes plotted in Fig. 4q. Cool PDO regimes are ev- 


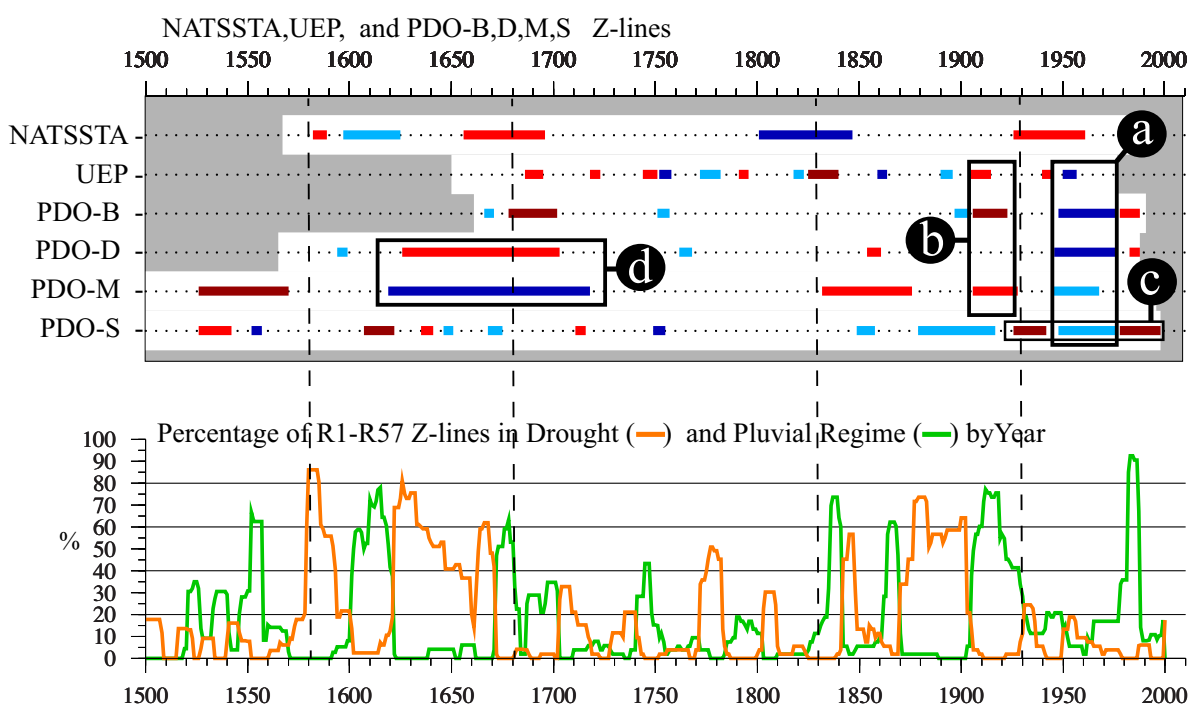

Figure A2. The optimal ranking regimes in Fig. A1e-f plotted as $Z$-lines. The significance shading scheme for $Z$ statistics is as shown at the top of Fig. A1. The (a-d) black frames outline regime features discussed in the Appendix A text. The lower panel reproduces Fig. 4q, which shows the percentage of Fig. 4's R1-R53 Z-lines that indicate significant drought or pluvial conditions $(|Z| \geq 1.96)$ during 1500-2000. Green traces indicate the percentage of lines in a pluvial regime, and orange traces show the percentage of lines in a drought regime during each year.

ident in all four PDO reconstructions and the UEP reconstruction during the 1940s to mid-1970s (Fig. A2a), which generally coincides with the 1947-1976 cool phase period defined by Mantua et al. (1997). Although the UEP, PDO-B and PDO-M reconstructions also show warm PDO regimes during 1905-1915, 1906-1923 and 1906-1928 (Fig. A2b), those periods precede the Mantua et al. (1997) 1925-1946 warm-phase PDO period. However, the regimes detected in the PDO-S reconstruction during the 20th century (Fig. A2c) more closely follow the Mantua et al. (1997) PDO phase periods, with warm-phase conditions during 1926-1942 and cool phase conditions during 1948-1977. After the mid 1970s, the warm-phase regime in the PDO-S reconstruction during 1978-1998 also closely coincides with the Mantua et al. (1997) warm-phase period after 1976. Although there is some agreement between the UEP and PDO reconstructions during the instrumental calibration periods (Table A1), there is virtually no agreement in the pre-instrumental period. In the one instance where the Pacific reconstructions show clearly concurrent regimes before 1900 , those regimes are of opposite sign, i.e., the PDO-M and PDO-D reconstructions roughly coincident cold and warm-phase regimes during 1619-1718 and 1626-1703 (Fig. A1d). As a result, the PDO and UEP indices show essentially no common behavior in the pre-instrumental period, and when compared with Fig. 4q, no evidence of centennial-scale periods of active and inactive variability.
In Fig. A2 during the 20th century the optimal ranking regimes of the NATSSTA reconstruction include a 1926-1961 warm regime, which nearly coincides with the 1931-1960 warm-phase period defined by Sutton and Hodson (2005). However, Sutton and Hodson (2005) also defined cool North Atlantic SSTA periods during 1905-1925 and 1965-1990, which the ORR procedure did not detect in the NATSSTA series at a $95 \%$ confidence level. The ORR analysis detected multi-decadal cool regimes in the reconstructed NATSSTA series during 1597-1625 and 1801-1847 and a warm regime during 1656-1696, but, like the Pacific analyses of Fig. A1b-f, shows no patterns of centennial variability similar to that of the reconstructed streamflow described in Sect. 4.4 and graphed in Figs. 4q and A2. 
Appendix B:

Table B1. As in Table 2 with an alternate random number generator seed.

\begin{tabular}{lrrrrrr}
\hline$|Z|$ Rank & Period & Duration & $Z$ & Period & Duration & $Z$ \\
\hline 1 & $1601-1621$ & 21 & 3.497 & $1870-1904$ & $\mathbf{3 5}$ & -2.727 \\
2 & $1982-1987 / 1836-1841$ & 6 & 3.068 & $1579-1592$ & 14 & -2.421 \\
3 & $1905-1928$ & $\mathbf{2 4}$ & 2.806 & $1772-1782$ & 11 & -2.344 \\
4 & $1672-1683$ & 12 & 2.541 & $1663-1671$ & 9 & -2.223 \\
5 & $1741-1747$ & 7 & 1.966 & $1622-1632$ & 11 & -2.203 \\
& Wet periods & & \multicolumn{3}{c}{ Dry periods } \\
\hline
\end{tabular}

Table B2. As in Tables 2 and B1 with an alternate random number generator seed.

\begin{tabular}{lrrrrrr}
\hline$|Z|$ Rank & Period & Duration & $Z$ & Period & Duration & $Z$ \\
\hline 1 & $1601-1621$ & 21 & 3.498 & $1870-1904$ & $\mathbf{3 5}$ & -2.742 \\
2 & $1982-1987 / 1836-1841$ & 6 & 3.064 & $1579-1592$ & 14 & -2.424 \\
3 & $1905-1928$ & $\mathbf{2 4}$ & 2.797 & $1772-1782$ & 11 & -2.331 \\
4 & $1672-1683$ & 12 & 2.523 & $1663-1671$ & 9 & -2.208 \\
5 & $1741-1747$ & 7 & 1.965 & $1622-1632$ & 11 & -2.191 \\
& Wet periods & & & \multicolumn{3}{c}{ Dry periods } \\
\end{tabular}

Table B3. As in Table 3 with an alternate random number generator seed.

\begin{tabular}{lrrrrrr}
\hline$|Z|$ Rank & Period & Duration & $Z$ & Period & Duration & $Z$ \\
\hline 1 & $1601-1621$ & 21 & 3.491 & $1622-1671$ & $\mathbf{5 0}$ & -2.679 \\
2 & $1836-1841$ & 6 & 3.250 & $1772-1782$ & 11 & -2.441 \\
3 & $1982-1987$ & 6 & 3.055 & $1874-1883$ & 10 & -2.196 \\
4 & $1905-1932$ & $\mathbf{2 8}$ & 2.658 & $1842-1847$ & 6 & -1.991 \\
5 & $1687-1702$ & 16 & 2.498 & $1528-1533$ & 6 & -1.913
\end{tabular}

Wet periods Dry periods

Table B4. As in Tables 3 and B3 with an alternate random number generator seed.

\begin{tabular}{lrrrrrr}
\hline$|Z|$ Rank & Period & Duration & $Z$ & Period & Duration & $Z$ \\
\hline 1 & $1601-1621$ & 21 & 3.498 & $1622-1671$ & $\mathbf{5 0}$ & -2.677 \\
2 & $1836-1841$ & 6 & 3.251 & $1772-1782$ & 11 & -2.449 \\
3 & $1982-1987$ & 6 & 3.056 & $1874-1883$ & 10 & -2.192 \\
4 & $1905-1932$ & $\mathbf{2 8}$ & 2.654 & $1842-1847$ & 6 & -1.992 \\
5 & $1687-1702$ & 16 & 2.493 & $1528-1533$ & 6 & -1.914 \\
\multicolumn{5}{c}{ Wet periods } & \multicolumn{5}{c}{ Dry periods } \\
\hline
\end{tabular}




\section{The Supplement related to this article is available online at doi:10.5194/cp-11-1107-2015-supplement.}

Acknowledgements. The calc_orr.c program and an associated shell script are available in the Supplement. Thanks to Matthew Becker and Justin DeRose of the Wasatch Dendroclimatology Research Group for the Weber River flow and the level of the Great Salt Lake reconstruction data, and to Z'ev Gedalof for the Columbia River flow reconstruction. All figures were produced using Generic Mapping Tools (Wessel and Smith, 1995). The US Department of Agriculture is an equal opportunity provider and employer.

Edited by: J. Luterbacher

\section{References}

Akaike, H.: A new look at the statistical model identification, IEEE T. Automat. Contr., 19, 716-723, 1974.

Barnett, F., Gray, S., and Tootle, G.: Upper Green River Basin (United States) streamflow reconstructions, J. Hydrol. Eng., 15, 567-579, 2010.

Bekker, M. F., DeRose, R. J., Buckley, B. M., Kjelgren, R. K., and Gill, N. S.: A 576-year Weber River streamflow reconstruction from tree rings for water resource risk assessment in the Wasatch Front, Utah, J. Am. Water Resour. As., 50, 1338-1348, 2014.

Biondi, F., Gershunov, A., and Cayan, D. R.: North Pacific decadal climate variability since 1661, J. Climate, 14, 5-10, 2001.

Biondi, F., Kozubowski, T. J., and Panorska, A. K.: Stochastic modeling of regime shifts, Climate Res., 23, 23-30, 2002.

Biondi, F., Kozubowski, T. J., and Panorska, A. K.: A new model for quantifying climate episodes, Int. J. Climatol., 25, 1253-1264, 2005.

Box, G. E. P. and Tiao, G. C.: Intervention analysis with applications to economic and environmental problems, J. Am. Stat. Assoc., 70, 70-79, 1975.

Brenneman, D.: Climate of rebellion: The relationship between climate variability and indigenous uprisings in mid-eighteenthcentury Sonora, PhD Dissertation, Univ. of Arizona Anthropology Dept., University of Arizona, Tucson, AZ, 2004.

Cayan, D. R., Dettinger, M. D., Diaz, H. F., and Graham, N. E.: Decadal variability of precipitation over western North America, J. Climate, 11, 3148-3166, 1998.

Cole J. E., Overpeck, J. T., and Cook, E. R.: Multiyear La Niña events and persistent drought in the contiguous United States, Geophys. Res. Lett., 29, 25-1-25-4, 2002.

Cook, E. R., Meko, D. M., Stahle, D. W., and Cleaveland, M. K.: Tree Rings, Environment, and Humanity, Eds., Radio- carbon, Tree-ring reconstructions of past drought across the conterminous United States: Tests of a regression method and calibration/verification results, in: Tree Rings, Environment, and Humanity, edited by: Dean, J. S., Meko, D. M., and Swetnam, T. W., Depart. Geosci., University of Arizona, Radiocarbon, Tucson, 155-169, 1996.
Cook, E. R., Meko, D. M., Stahle, D. W., and Cleaveland, M. K.: Drought Reconstructions for the Continental United States, J. Climate, 12, 1145-1162, 1999.

Cook, E. R., Woodhouse, C. A., Eakin, C. M., Meko, D. M., and Stahle, D. W.: Long-term aridity changes in the western United States, Science, 306, 1015-1018, 2004.

Cook, E. R., Seager, R., Cane, M. A., and Stahle, D. W.: North American drought: Reconstructions, causes, and consequences, Earth-Sci. Rev., 81, 93-134, 2007.

Cordero, E., Kessomkiat, W., Abatzoglou, J., and Mauget, S.: The identification of distinct patterns in California temperature trends, Climatic Change, 108, 357-382, 2011.

Creasman, P. P., Bannister, B., Towner, R. H., Dean, J. S., and Leavitt, S. W.: Reflections on the foundation, persistence, and growth of the Laboratory of Tree-Ring Research, circa 1930-1960, TreeRing Research, 68, 81-89, 2012.

Dai, A.: The influence of the inter-decadal Pacific oscillation on US precipitation during 1923-2010, Climate Dynamics, 41, 633646, 2013.

D'Arrigo, R. and Wilson, R.: On the Asian expression of the PDO, Int. J. Climatol., 26, 1607-1617, 2006.

D’Arrigo, R., Wilson, R., Deser, C., Wiles, G., Cook, E., Villalba, R., Tudhope, A., Cole, J., and Linsley, B.: Tropical-North Pacific climate linkages over the past four centuries, J. Climate, 18, 5253-5265, 2005.

DeRose, R. J., Wang, S.-Y., Buckley, B. M., and Bekker, M. F.: Tree-ring reconstruction of the level of Great Salt Lake, USA, The Holocene, 24, 805-813, 2014.

Dracup, J. A., Lee, K. S., and Paulson, E.G. : On the Definition of Droughts, Water Resour. Res., 16, 297-302, 1980.

Fritts, H. C.: Tree Rings and Climate, Academic Press, London, 1976.

Fye, F. K., Stahle, D. W., and Cook, E. R.: Paleoclimatic Analogs to Twentieth-Century Moisture Regimes Across the United States, Bullett. Am. Meteorol. Soc., 84, 901-909, 2003.

Gedalof, Z. and Smith, D. J.: Interdecadal climate variability and regime-scale shifts in Pacific North America, Geophys. Res. Lett., 28, 1515-1518, 2001.

Gedalof, Z., Peterson, D. L., and Mantua, N.: Columbia River Flow and Drought since 1750, J. Am. Water Resour. As., 40, 15791592, 2004.

Goodrich, G. B.: Multidecadal Climate Variability and Drought in the United States, Geography Compass, 1, 713-738, 2007.

Gray, S. T., Betancourt, J. L., Fastie, C. L., and Jackson, S. T.: Patterns and sources of multidecadal oscillations in drought-sensitive tree-ring records from the central and southern Rocky Mountains, Geophys. Res. Lett., 30, 1316, doi:10.1029/2002GL016154, 2003.

Gray, S. T., Graumlich, L. J., Betancourt, J. L., and Pederson, G. T.: A tree-ring based reconstruction of the Atlantic Multidecadal Oscillation since 1567 A.D., Geophys. Res. Lett., 31, L12205, doi:10.1029/2004GL019932, 2004.

Gray, S. T., Lukas, J. J., and Woodhouse, C. A.: Millennial-Length Records of Streamflow From Three Major Upper Colorado River Tributaries, J. Am. Water Resour. As., 47, 702-712, 2011.

Griffin, R. D.: A 600-Year Streamflow History in the Salinas Valley Reconstructed from Blue Oak Tree Rings, M. A. Thesis, University of Arkansas, Fayetteville, 67 pp., 2007. 
Hidalgo, H. G.: Climate precursors of multidecadal drought variability in the western United States, Water Resour. Res., 40, W12504, doi:10.1029/2004WR003350, 2004.

Hidalgo, H. G., Piechota, T. C., and Dracup, J. A.: Alternative principal components regression procedures for dendrohydrologic reconstructions, Water Resour. Res., 36, 3241-3249, 2000.

Hirschboeck, K. K. and Meko., D. M.: The Current Drought In Context: A Tree-Ring Based Evaluation of Water Supply Variability for the Salt-Verde River Basin Final Report, University of Arizona Laboratory of Tree-Ring Research \& The Salt River Project, Tucson, AZ, 29 pp., 2008.

Hoerling, M., Hurrell, J., Kumar, A., Terray, L., Eischeid, J., Pegion, P., Zhang, T., Quan, X., and Xu, T.: On North American Decadal Climate for 2011-2020, J. Climate, 24, 4519-4528, 2011.

Hollander, M. and Wolfe, D. A.: Nonparameteric Statistical Methods, Wiley and Sons, Hoboken, 1999.

Hundley, N.: Water and the West: The Colorado River Compact and the Politics of Water in the American West, University of California Press, Oakland, CA, 2009.

MacDonald, G. M. and Case, R. A.: Variations in the Pacific Decadal Oscillation over the past millennium, Geophys. Res. Lett., 32, L08703, doi:10.1029/2005GL022478, 2005.

MacDonnell, L. J., Getches, D. H., and Hugenberg, W. C.: The Law of the Colorado River: Coping with Severe Sustained Drought, J. Am. Water Resour. As., 31, 825-836, 1995.

Mann, H. B. and Whitney, D. R.: On a Test of Whether One of Two Random Variables is Stochastically Larger than the Other, Ann. Math. Stat., 18, 50-60, 1947.

Mantua, N. J. and Hare, S. R.: The Pacific Decadal Oscillation, J. Oceanogr., 58, 35-44, 2002.

Mantua, N. J., Hare, S. R., Zhang, Y., Wallace, J. M., and Francis, R. C.: A Pacific Interdecadal Climate Oscillation with Impacts on Salmon Production, Bullett. Am. Meteorol. Soc., 78, 1069-1079, 1997.

Margolis, E. Q., Meko, D. M., and Touchan, R.: A tree-ring reconstruction of streamflow in the Santa Fe River, New Mexico, J. Hydrol., 397, 118-127, 2011.

Masiokas, M. H., Villalba, R., Christie, D. A., Betman, E., Luckman, B. H., Le Quesne, C., Prieto, M. R., and Mauget, S.: Snowpack variations since AD 1150 in the Andes of Chile and Argentina $\left(30-37^{\circ} \mathrm{S}\right)$ inferred from rainfall, tree-ring and documentary records, J. Geophys. Res.-Atmos., 117, D05112, doi:10.1029/2011JD016748, 2012.

Mauget, S. A.: Intra- to Multidecadal Climate Variability over the Continental United States: 1932-99, J. Climate, 16, 2215-2231, 2003a.

Mauget, S. A.: Multidecadal Regime Shifts in US Streamflow, Precipitation, and Temperature at the End of the Twentieth Century, J. Climate, 16, 3905-3916, 2003 b.

Mauget, S. A.: Low Frequency Streamflow Regimes over the Central United States: 1939-1998, Climatic Change, 63, 121-144, 2004.

Mauget, S. A. and Cordero, E. C.: Optimal Ranking Regime Analysis of Intra- to Multi-Decadal US Climate Variability - Part I: Temperature, J Climate, 27, 9006-9026, 2014a.

Mauget, S. A. and Cordero, E. C.: Optimal Ranking Regime Analysis of Intra- to Multi-decadal US Climate Variability - Part II: Precipitation and Streamflow, J. Climate, 27, 9027-9049, 2014 b.
McCabe, G. J. and Wolock, D. M.: Variability Common to Global Sea Surface Temperatures and Runoff in the Conterminous United States, J. Hydrometeorol., 15, 714-725, 2013.

McCabe, G. J., Palecki, M. A., and J. Betancourt, J .L.: Pacific and Atlantic Ocean influences on multidecadal drought frequency in the United States, Proc. Natl. Acad. Sci. USA, 101, 4136-4141, 2004.

McCabe, G. J., Betancourt, J. L., and Hidalgo, H. G.: Associations of Decadal to Multidecadal Sea-Surface Temperature Variability with Upper Colorado River Flow, J. Am. Water Resour. As., 43, 183-192, 2007.

McGregor, S., Timmermann, A., and Timm, O.: A unified proxy for ENSO and PDO variability since 1650, Clim. Past, 6, 1-17, doi:10.5194/cp-6-1-2010, 2010.

Meko, D. M.: Dendroclimatic Reconstruction with Time Varying Predictor Subsets of Tree Indices, J. Climate, 10, 687-696, 1997.

Meko, D. M. and Woodhouse, C. W.: Application of Streamflow Reconstruction to Water Resources Management, in: Dendroclimatology: Progress and Prospects, edited by: Hughes, M. K., Swetnam, T. W., and Diaz, H. F., Developments in Paleoenvironmental Research, Springer, New York, 231-261, 2011.

Meko, D. M., Stockton, C. W., and Boggess, W. R.: The tree ring record of severe sustained drought, J. Am. Water Resour. As., 31, 789-801, 1995.

Meko, D. M., Therrell, M. D., Baisan, C. H., and Hughes, M. K.: Sacramento river flow reconstructed to A.D. 869 from tree rings, J. Am. Water Resour. As., 37, 1029-1039, 2001.

Meko, D. M., Woodhouse, C. A., Baisan, C. A., Knight, T., Lukas, J. J., Hughes, M. K., and Salzer, M. W.: Medieval drought in the upper Colorado River Basin, Geophys. Res. Lett., 34, L10705, doi:10.1029/2007GL029988, 2007.

Mendenhall, W., Wackerly, D. D., and Sheaffer, R. L.: Mathematical Statistics with Applications. PWS-Kent, Boston, 1990.

Nash, S. E.: Time, Trees, and Prehistory: Tree Ring Dating and the Development of North American Archaeology 1914-1950, The University of Utah Press, Salt Lake City, 1999.

Pagano, T., Pasteris, P., Dettinger, M., Cayan, D., and Redmond, K.: Water year 2004: Western water managers feel the heat, Eos, Trans. Am. Geophys. Union, 85, 385-393, 2004.

PAGES 2k Consortium: Continental-scale temperature variability during the past two millennia, Nat. Geosci., 6, 339-346, 2013.

Piechota, T., Timilsena, J., Tootle, G., and Hidalgo, H: The western US drought: How bad is it? Eos, Transactions, Am. Geophys. Union, 85, 301-308, 2004

Redmond, K. T. and Koch, R. W.: Surface Climate and Streamflow Variability in the Western United States and Their Relationship to Large-Scale Circulation Indices, Water Resour. Res., 27, 23812399, 1991.

Rice, J. L., Woodhouse, C. A., and Lukas, J. J.: Science and Decision Making: Water Management and Tree-Ring Data in the Western United States, J. Am. Water Resour. As., 45, 1248-1259, 2009.

Schubert, S. D., Suarez, M. J., Pegion, P. J., Koster, R. D., and Bacmeister, J. T.: Causes of Long-Term Drought in the US Great Plains, J. Climate, 17, 485-503, 2004.

Schubert, S. D., Suarez, M. J., Pegion, P. J., Koster, R. D., and Bacmeister, J. T.: Potential Predictability of Long-Term Drought and Pluvial Conditions in the US Great Plains, J. Climate, 21, 802-816, 2008. 
Shen, C., Wang, W., Gong, W., and Hao, Z.: A Pacific Decadal Oscillation record since $1470 \mathrm{AD}$ reconstructed from proxy data of summer rainfall over eastern China, Geophys. Res. Lett., 33, L03702, doi:10.1029/2005GL024804, 2006.

Solomon, A., Goddard, L., Kumar, A., Carton, J., Deser, C., Fukumori, I., Greene, A. M., Hegerl, G., Kirtman, B., Kushnir, Y., Newman, M., Smith, D., Vimont, D., Delworth, T., Meehl, G. A., and Stockdale, T.: Distinguishing the Roles of Natural and Anthropogenically Forced Decadal Climate Variability, Bullett. Am. Meteorol. Soc., 92, 141-156, 2010.

Stahle, D. W. and Dean, J. S.: North American Tree Rings, Climate Extremes, and Social Disasters, in: Dendroclimatology: Progress and Prospects, edited by: Hughes, M. K., Swetnam, T. W., and Diaz, H. F., Developments in Paleoenvironmental Research, Springer, New York, 297-327, 2011.

Stahle, D. W., Cook, E. R., Cleaveland, M. K., Therrell, M. D., Meko, D. M., Grissino-Mayer, H. D., Watson, E., and Luckman, B. H.: Tree-ring Data Document 16th Century Megadrought Over North America, Eos, Trans. Am. Geophys. Union, 81, 121$125,2000$.

Stahle, D. W., Therrell, M. D., Cleaveland, M. K., Cayan, D. R., Dettinger, M. D., and Knowles, N.: Ancient blue oaks reveal human impact on San Francisco Bay salinity, Eos, Trans. Am. Geophys. Union, 82, 141-145, 2001.

Stahle, D. W. Fye, F. K, Cook, E. R., and Griffin, R. D.: Tree-ring reconstructed megadroughts over North America since A.D. 1300, Climatic Change, 83, 133-149, 2007.

Stockton, C. W. and Jacoby, G. C.: Long-term surface-water supply and streamflow trends in the Upper Colorado River Basin, Lake Powell., Natl. Sci. Found., Arlington, VA, 1976.

Sutton, R. T. and Hodson, D. L. R.: Atlantic Ocean Forcing of North American and European Summer Climate, Science, 309, 115$118,2005$.

Villalba, R., D’Arrigo, R., Cook, E., Wiles, G., and Jacoby, G.: Decadal-scale climatic variability along the extratropical western coast of the Americas: Evidence from tree-ring records, in: InterHemispheric Climate Linkages, edited by: Markgraf, V., Academic Press, San Diego, 155-172, 2001.
Villalba, R., Luckman, B. H., Bosinsegna, J., D’ Arrigo, R. D., Lara, A., Villenueva-Diaz, J., Masiokas, M., Argollo, J., Soliz, C., LeQuesne, C., Stahle, D. W., Roig, F., Aravena, J. C., Hughes, M. K., Wiles, G., Jacoby, G., Hartsough, P., Wilson, R. J. S., Watson, E., Cook, E. R., Serano-Paredes, J., Therrell, M., Cleaveland, M., Morales, M. S., Graham, N. E., Moya, J., Pacajes, J., Massacchesi, G., Biondi, F., Urrutia, R., and Pastur, G. M.: Dendroclimatology from Regional to Continental Scales: Understandimg Regional Processes to Reconstruct Large Scale Climate Variations Across the Western Americas, in: Dendroclimatology: Progress and Prospects, edited by: Hughes, M.K., Swetnam, T. W., and Diaz, H. F., Springer, New York, 175-227, 2011.

Watson, T. A., Anthony, B.F., Gray, S. T., and Tootle, G. A.: Reconstructed Streamflows for the Headwaters of the Wind River, Wyoming, United States, J. Am. Water Resour. As., 45, 224-236, 2009.

Wessel, P. and Smith, W. H. F.: New version of the generic mapping tools, Eos, Trans. Am. Geophys.Union, 76, 329-329, 1995.

Wilks, D. S.: Statistical Methods in the Atmospheric Sciences, Academic Press, San Diego, 1995.

Wise, E. K.: Tree ring record of streamflow and drought in the upper Snake River, Water Resour. Res., 46, W11529, doi:10.1029/2010WR009282, 2010.

Woodhouse, C. A. and Lukas, J. J.: Multi-Century Tree-Ring Reconstructions of Colorado Streamflow for Water Resource Planning, Climatic Change, 78, 293-315, 2006a.

Woodhouse, C. A. and Lukas, J. J.: Streamflow Reconstructions for Boulder Creek, South Boulder Creek, and the Colorado River, City of Boulder and Hydrosphere Resource Consultants, Boulder, CO, 2006b.

Woodhouse, C. A. and Lukas, J. J.: Tree-ring reconstruction of Clear Creek annual streamflow, 1566-2002, Report to City of Westminster, Westminster, CO, 2006c.

Woodhouse, C. A. and Overpeck, J. T.: 2000 Years of Drought Variability in the Central United States, Bullett. Am. Meteorol. Soc. 79, 2693-2714, 1998.

Woodhouse, C. A., Lukas, J. J., and Brown, P. M.: Drought in the Western Great Plains, 1845-56, Bullett. Am. Meteorol. Soc., 83, 1485-1493, 2002.

Woodhouse, C. A., Kunkel, K. E., Easterling, D. R., and Cook, E. R.: The twentieth-century pluvial in the western United States, Geophys. Res. Lett., 32, L07701, doi:10.1029/2005GL022413, 2005.

Woodhouse, C. A., Gray, S. T., and Meko, D. M.: Updated streamflow reconstructions for the Upper Colorado River Basin, Water Resour. Res., 42, W05415, doi:10.1029/2005WR004455, 2006. 